Article

\title{
Nicotine neurotoxicity involves low Wnt1 signaling in spinal locomotor networks of the postnatal rodent spinal cord
}

\author{
Jaspreet Kaur 1,3, ${ }^{\text {, }}$ Graciela L. Mazzone ${ }^{2,3, *}$, Jorge B. Aquino ${ }^{2}$, Andrea Nistri ${ }^{3}$ \\ 1 Faculty of Health and Medical Sciences, Department of Neuroscience, University of Copenhagen, Bleg- \\ damsvej 3, DK-2200 KBH N, Denmark; jaspreet.kaur@sund.ku.dk (J.K.) \\ 2 Instituto de Investigaciones en Medicina Traslacional (IIMT), CONICET-Universidad Austral, Av. Pte. Pe- \\ rón 1500, B1629AHJ, Pilar, Buenos Aires, Argentina; GMazzone@austral.edu.ar (G.L.M.); jaquino@aus- \\ tral.edu.ar (J.B.A.) \\ 3 Department of Neuroscience, International School for Advanced Studies (SISSA), Trieste, Italy; nis- \\ tri@sissa.it (A.N.) \\ * Correspondence: jaspreet.kaur@sund.ku.dk (J.K.); GMazzone@austral.edu.ar (G.L.M.); Tel.: +45-52601502 \\ (J.K.); +54-2304387425 (G.L.M.)
}

\begin{abstract}
The postnatal rodent spinal cord in-vitro is a useful model to investigate early pathophysiological changes after injury. While low dose nicotine $(1 \mu \mathrm{M})$ induces neuroprotection, how higher doses affect spinal networks is unknown. Using spinal preparations of postnatal wild-type Wistar rat and Wnt1Cre2:Rosa26Tom double-transgenic mouse, we studied the effect of nicotine (0.5$10 \mu \mathrm{M}$ ) on locomotor networks in-vitro. Nicotine $10 \mu \mathrm{M}$ induced motoneuron depolarization, suppressed monosynaptic reflexes, and decreased fictive locomotion in rat spinal cord. Delayed fall in neuronal numbers (including motoneurons) of central and ventral regions emerged without loss of dorsal neurons. Conversely, nicotine $(0.5-1 \mu \mathrm{M})$ preserved neurons throughout the spinal cord and strongly activated the Wnt1 signaling pathway. High-dose nicotine enhanced expression of S100 and GFAP in astrocytes suggesting their response to stress. Excitotoxicity induced by kainate was contrasted by nicotine $(10 \mu \mathrm{M})$ in the dorsal area and persisted in central and ventral regions with no change basal Wnt signaling. When combining nicotine with kainate, the activation of Wnt 1 was reduced compared to kainate/sham. The present results suggest that high dose nicotine was neurotoxic to central and ventral spinal neurons as the neuroprotective role of Wnt signaling became attenuated. This also corroborates the risk of cigarette smoking for the foetus/newborn since tobacco contains nicotine.
\end{abstract}

Keywords: Nicotine toxicity; Wnt1 pathway; spinal cord injury; locomotor networks; excitotoxicity; fictive locomotion; postnatal; rat; mice

\section{Introduction}

Transient application of nicotine to brain and spinal motor networks in vitro can robustly protect them from excitotoxicity and neurodegeneration $[1 ; 2 ; 3]$. In particular, using the isolated rodent spinal cord maintained in vitro for $24 \mathrm{~h}$ as a model of acute spinal injury [4; 5], we have observed that nicotine evokes a neuroprotective action against excitotoxic damage induced by the glutamate agonist kainate; KA [2]. The translational implication of these data suggests that the role of nicotine might extend beyond its well-known effect of alleviating certain forms of chronic pain in human [6], a phenomenon at least in part attributable to positive modulation of inhibitory synaptic transmission in the spinal cord $[7 ; 8 ; 9]$. Nevertheless, acute administration of nicotine to smokers with spinal cord injury (SCI) induces a sharp increase in neuropathic pain [6], demonstrating a dual action of nicotine. Thus, in a spinal cord model we set out to investigate the borderline between neuroprotection and toxicity exerted by nicotine to discover mechanisms that could contrast this transition. In particular, although the neurotoxicity of nicotine is widely documented [10], especially in young people [11], little is 
known about its possible toxic effects on spinal networks. Although high-dose nicotine is a well-known proconvulsive and convulsive agent that activates brain centers [12; 13], whether nicotine can cause hyperexcitability or depression of spinal circuitries is unclear.

In the mouse hippocampus, during the process of neuroprotection against various insults, nicotine activates Wnt (Wingless-related MMTV integration site) signaling pathways which in turn upregulate $\alpha 7$ nicotinic acetylcholine receptors (nAChRs) via transcriptional activation of Wnt target genes related to survival [14]. Either short (30 min) or $24 \mathrm{~h}$ application of nicotine is reported to positively regulate Wnt via a PKC-dependent process in cultured cells [15].

The Wnt/ $\beta$-catenin signaling pathway comprises a family of secreted lipid-modified glycoproteins involved in cell-cell communication through intercellular signaling [16; 17], with an essential role in vertebrate development [18; 19] including spinal cord dorsal-ventral patterning [20]. Furthermore, the direction of axon movement and specific innervation depend on Wnt signaling mechanisms [19; 21]. Wnt1 and Wnt3a are expressed in extensively overlapping regions within the central nervous system, predominantly along the dorsal midline from the diencephalon to the spinal cord, and are required for the specification of dorsal interneurons [20]. The signaling pathways involved in neuronal recovery and regeneration following spinal cord and peripheral nerve injury have garnered growing attention. Within this framework, an in vitro study has shown that inactivation of Wnt signaling depresses spinal excitatory synaptic transmission [22]. An increase in the expression levels of Ryk, a Wnt receptor, was found a few hours after contusion of the rat spinal cord, consistent with an early involvement of this signaling pathway in the pathophysiology of SCI [23]. Furthermore, recent studies have demonstrated that, after blocking Wnt/Ryk receptor signaling, progression of neuropathic pain due to spinal nerve ligation is reduced [24]. Wnts can also modulate astrocyte function [25] and contribute to the formation of glial scars after SCI in adult rats [26]. Wnt1 is reported to promote the expression of the glial glutamate transporter EAAT2, which has been associated with astrocyte-mediated protection in cultured dopaminergic cells through the decrease in the concentration of extracellular glutamate [27]. It, therefore, appears that the $\mathrm{Wnt} / \beta$-catenin signaling pathway may contribute to certain neuroprotective effects as, in a rat SCI model, its induction results in significant locomotion improvements [28]. Thus, it seemed interesting to study changes in the expression of Wnts in the spinal cord tissue in response to an acute treatment with nicotine or kainate (as an experimental excitotoxic stimulus) or a combination of both.

Hence, the aims of the present study were to investigate the effect of high-dose nicotine $(10 \mu \mathrm{M})$, as well as of its interaction with kainate, on synaptic transmission and rhythmic output of motor networks, neuronal and astroglia numbers, and the activation of the Wnt1 promoter. To this end, we used in vitro spinal cord preparations of wild-type rat as well as transgenic mice expressing Wnt1Cre2:Rosa26Tom for interrogating gene function and activity. The Wnt1Cre2 transgenic mouse line includes the Wnt1 promoter and enhancer sequences without the gene sequence itself. Indeed, crossing this transgenic mouse with Rosa26Tom reporter mouse produces a useful model for studying the differentiation of neuronal subtypes and drive gene expression with the purpose of designing restorative therapies [29]. 


\section{Results}

\subsection{Dose-dependent effect of nicotine on network depolarization, Wnt1 path- way and neuronal numbers}

Figure 1. A shows representative examples of the ventral root (VR; left L5) depolarization (representing the integrated output of motoneuron pools) evoked by nicotine applied at various concentrations up to $10 \mu \mathrm{M}$ (Nic 10). The bar chart of Figure 1. B shows that Nic 10 induced significant depolarization that persisted for several min as exemplified in Figure 1. A. Statistical analysis confirmed that the depolarization response to 10 $\mu \mathrm{M}$ nicotine was the strongest one (Nic 10 vs Baseline: $\mathrm{P}=<0.001, t=8.416$; Nic 2 vs Baseline: $\mathrm{P}=0.001, t=4.862$; Nic 1 vs Baseline: $\mathrm{P}=0.004, t=4.033$; Nic 0.5 vs Baseline: $\mathrm{P}=$ $0.004, t=4.1$, Holm-Sidak Method). Furthermore, the highest nicotine dose also elicited a flurry of high frequency discharges indicating repeated firing of motoneurons. Although $10 \mu \mathrm{M}$ nicotine has previously been shown to exert neuroprotective effects on hypoglossal motoneurons in rats [1], the extent and duration of such effect on spinal networks suggested its potential neurotoxicity. To further investigate this phenomenon which presumably developed slowly, the effect of different nicotine concentrations on the number of neurons (immunolabeled for the specific NeuN marker) and the activation of Wnt1 were analyzed $24 \mathrm{~h}$ later by using slices from the lumbar spinal cord of Wnt1Cre2:Rosa26Tom mice. The application of 0.5 and $1 \mu \mathrm{M}$ nicotine for $4 \mathrm{~h}$ exhibited a neuroprotective effect on such neurons in the ventral horn as their number was higher than in sham preparations 24 later, thus, suggesting that this drug had likely slowed down the standard neuronal loss usually occurring during long in vitro maintenance. Conversely, the neuronal number was significantly reduced $24 \mathrm{~h}$ after Nic 10 administration (Figure 2. A, upper panel; sham vs Nic 10: $\mathrm{P}=0.01, \mathrm{U}=53.5$, Mann-Whitney test). Application of $0.5 \mu \mathrm{M}$ of nicotine largely increased Wnt1 signal compared to sham, an effect observed at lesser extent when higher doses were applied (Figure 2. A, lower panel, and B; sham vs Nic 0.5: $\mathrm{P}=<0.001, t_{17.487}=-6.83$, Welch's $t$ test; sham vs Nic $1: \mathrm{P}=$ $<0.001, t_{24.845}=-3.808$, Welch's $t$ test; sham vs Nic $10: \mathrm{P}=<0.001, t_{31.645}=-8.592$, Welch's $t$ test). Supplemental Fig. 1 B shows, in a transverse section of the mouse spinal cord, broad expression of the Wnt1 signal in the blood vessels, by colocalization of CD31 antibody labelling [30]. The Pearson correlation coefficient (PCC) was used to quantify the degree of colocalization between Wnt1 signal with a neuronal (NeuN), glial (S100) or blood vessels (CD31) marker [31]. Costes et al. [32] methodology approach for automatically identifying the threshold value was used to identify background based on an analysis that determines the range of pixel values for which a positive PCC was obtained by using FiJi software. The analysis of the Wnt1 signal in fluorescence microscopy images over the entire ventral spinal region indicated high distribution in blood vessels (Supplemental Fig. 1 B) with sample images of positive signals for both probes shown in white. When red and green pixel intensities were quantified by PCC, a significant increase was observed for CD31 $(0.87 \pm 0.01)$ vs S100 $(0.41 \pm 0.05)$ and vs NeuN $(0.20 \pm 0.07)$, respectively (S100 vs CD31: P < 0.005; NeuN vs CD31: P < 0.05, U = 10.71; Dunn's Method). 
A

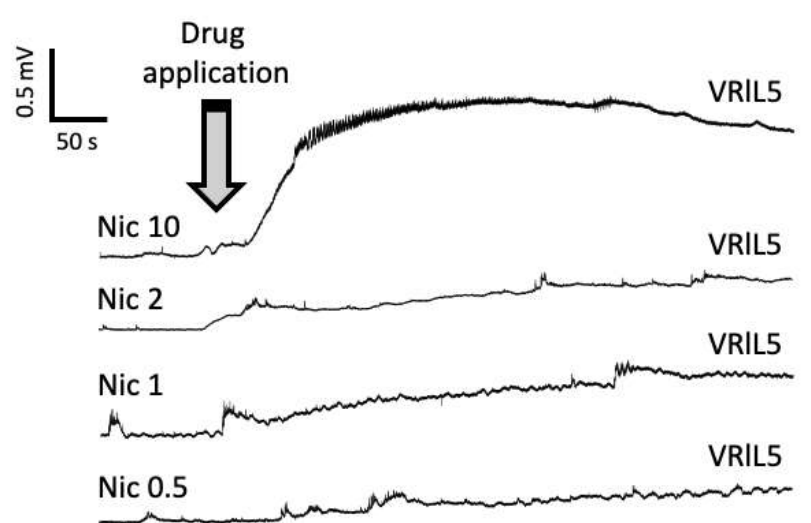

B

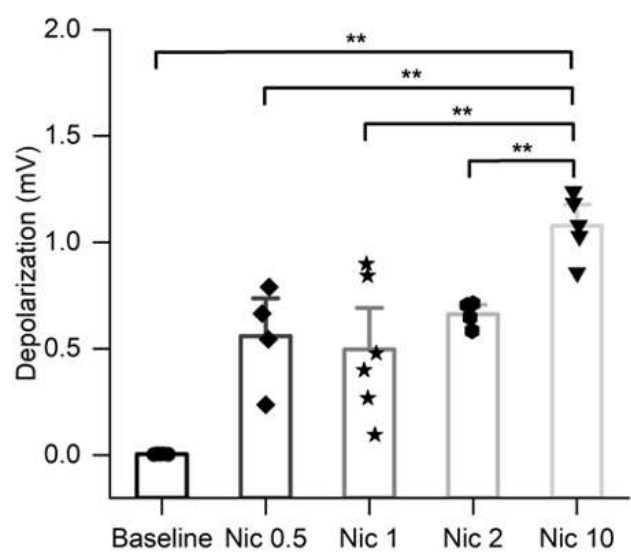

Figure 1. VR depolarization responses induced by applying different nicotine (Nic) doses to the rat spinal cord. (A) Sample recordings with Nic $10(n=5), 2(n=4), 1(n=6)$ and $0.5(n=4) ; \mu M$ where a grey arrow designates the beginning of drug administration. (B) Histogram shows baseline $(n=5)$ and depolarization responses induced by Nic $0.5,1$ and 2 with large effect evoked by Nic 10 in comparison to lower Nic doses (Nic 0.5 vs Nic $10: P=0.01, t 4.818=-3.813$, Welch's $t$ test; Nic 1 vs Nic 10: $P=0.005, t 7.337=-3.987$, Welch's $t$ test; Nic 2 vs Nic 10: $P=0.002$, t5.486 $=-5.706$, Welch's $t$ test). Note that $\mathrm{n}$ is the number of spinal cords used.

A

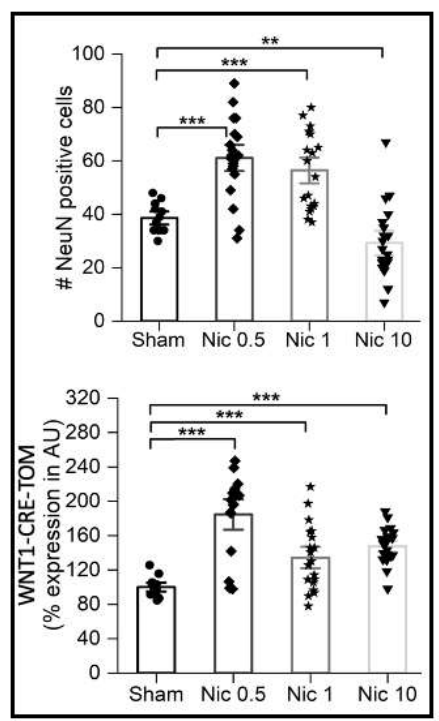

B Ventral spinal region Wnt1Cre2:Rosa26Tom Sham
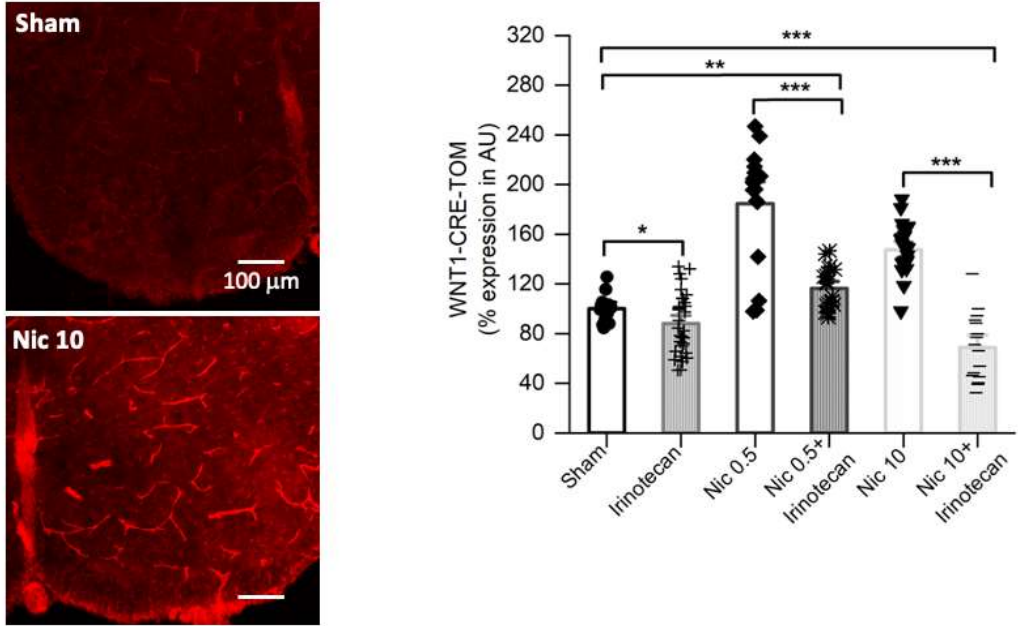

Figure 2. Effect of different doses of nicotine on neuronal numbers and Wnt1 pathway in mouse spinal ventral region. (A) Top panel: no change in neuronal numbers after low nicotine doses $(0.5$ and $1 \mu \mathrm{M})$ while a significant decrease was observed with10 $\mu \mathrm{M}$ nicotine in comparison to sham (Nic 10, A upper panel; sham vs Nic 10: $\mathrm{P}=0.01, \mathrm{U}=53.5$, MannWhitney test). Lower panel shows effects of nicotine on Wnt1 immunolabeling whereby Nic 0.5 intensified Wnt1 expression (sham vs Nic 0.5: $\mathrm{P}=<0.001, t_{17.487}=-6.83$, Welch's $t$ test) while Nic 1 (Nic 0.5 vs Nic $1: \mathrm{P}=0.002, t_{28.05}=3.452$, Welch's $t$ test) or 10 elicited a clearly smaller response (Nic 0.5 vs Nic $10: P=0.009, t_{18.95}=2.94$, Welch's $t$ test). (B) Example images of Wnt1 signal in the ventral region for control condition and after nicotine application where Nic 10 application shows an increase in Wnt1 expression. (C) Irinotecan significantly decreased Wnt1 expression (sham vs Irinotecan: $\mathrm{P}=0.038, t_{38.62}=2.148$, Welch's $t$ test), prevented the rise by $\mathrm{Nic} 0.5$ (Nic 0.5 vs Irinotecan $+\mathrm{Nic} 0.5: \mathrm{P}=0.003$, $t_{19.19}=3.42$, Welch's $t$ test), and lowered it below control after Nic 10 (sham vs Irinotecan+Nic $10: P=0.001, t_{21.87}=4.11$, Welch's $t$ test; Nic 10 vs Irinotecan+Nic 10: $\mathrm{P}<=0.001, t_{26.495}=9.82$, Welch's $t$ test). Sham: $\mathrm{n}=3$; Nic 0.5: $\mathrm{n}=5$; Nic $1: \mathrm{n}=5$; 
Nic 10: $n=5$; Irinotecan, $n=8$; Nic 10+Irinotecan, $n=4$, where $\mathrm{n}$ is the number of spinal cords used. Note that 3-4 slices were analyzed per spinal cord. Scale bar $(100 \mu \mathrm{m})$ applies to all panels.

These results are consistent with previous reports showing a neuroprotective effect of $1 \mu \mathrm{M}$ nicotine to spinal locomotor networks [2] and suggest a narrow range of nicotine levels near the border between a neuroprotective and a toxic effect.

To support a possible involvement of the Wnt1 signaling pathway, the Wnt1 antagonist irinotecan was applied at a concentration of $5 \mu \mathrm{M}[33 ; 34]$ (Figure 2. C) and was found to partially inhibit the expression of Wnt1-Cre-Tom compared to sham and to prevent the rise elicited by 0.5 or $10 \mu \mathrm{M}$ nicotine on the activation of the Wnt 1 promoter $(\mathrm{P}<$ $0.001, F_{5,121}=14.47$, One Way Analysis of Variance test).

\subsection{Effect of high nicotine levels on rat spinal neurons and motoneurons}

To investigate the topology of the effect of a high dose of nicotine on rat spinal neurons and motoneurons, neuronal $(\mathrm{NeuN}+$ ) numbers from the dorsal $(\mathrm{D})$, central $(\mathrm{C})$, and ventral (V) regions and ventral motoneurons (immunostained for SMI32) were quantified. After nicotine application $(4 \mathrm{~h})$, no change was found in the number of dorsal neurons 24 h later; however, a significant decrease was observed in regions $\mathrm{C}$ and $\mathrm{V}$ (Figure 3. A and B; $P=<0.001, F_{5,53}=127.77$, One Way Analysis of Variance test) and among ventral motoneurons (Figure 3. A and C), compared to sham. These data suggest a neurotoxic effect of high nicotine on certain spinal neurons and motoneurons particularly in the regions believed to be essential for generating the locomotor rhythm $[35 ; 36]$.

A

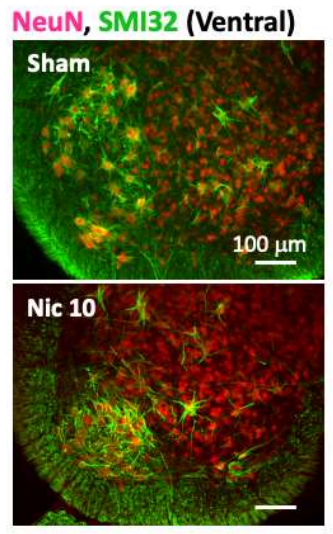

B

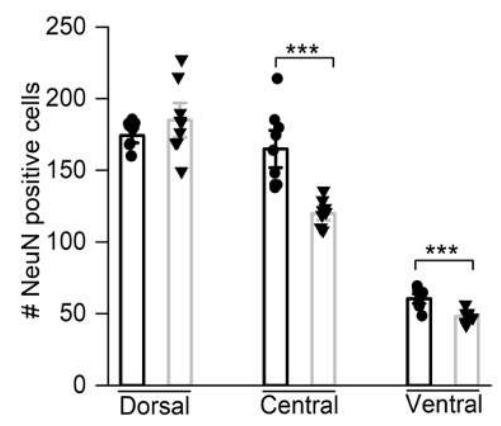

C

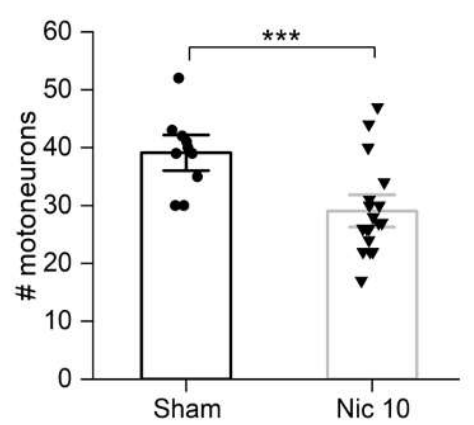

Figure 3. Changes in neuronal and motoneuronal numbers after incubation with Nic $10(n=3)$ in rat spinal cord. $(\mathrm{A}, \mathrm{B})$ No modulation in the number of neurons (immunolabelled by NeuN, red in panel A) in the dorsal horn (D; sham vs Nic 10: $\mathrm{P}=0.238, t_{10.781}=-1.249$, Welch's $t$ test $)$ whereas significant reduction in the central $(C$; sham vs $N i c 10: P=<0.001$, $t_{10.034}=4.903$, Welch's $t$ test $)$ and the ventral $\left(\mathrm{V}\right.$; sham vs Nic $10: \mathrm{P}=<0.001, t_{13.722}=4.658$, Welch's $t$ test) regions occurred $(\mathrm{n}=3)$. (A, C) Spinal motoneurons immunolabelled by SMI32 were substantially decreased after Nic 10 application $(\mathrm{P}=$ $0.001, t_{22.002}=3.637$, Welch's $t$ test). A minimum of 3 slices was analyzed per spinal cord, therefore 9 slices were analyzed per treatment. Scale bar $(100 \mu \mathrm{m})$ applies to all panels.

\subsection{Upregulation of $S 100$ and GFAP by nicotine $10 \mu \mathrm{M}$}

A strong increase in GFAP expression in fetal brain has previously been reported after exposure to nicotine [37]. Here, similar results were obtained in the spinal cord of newborn rodents $24 \mathrm{~h}$ after the application of Nic 10 for $4 \mathrm{~h}$. Astroglia response to treatment with Nic 10 was monitored with S100 (Figure 4. A, upper panel; sham: $n=10$; Nic 
10: $n=7$ ) and GFAP (Figure 4. A lower panel; sham: $n=6$; Nic 10: $n=4$ ) immunostaining in postnatal rat spinal preparations. The Nic 10 treatment induced an overexpression of S100 in all spinal regions D, C and V $\left(\mathrm{P}=<0.001, \mathrm{~F}_{5,50}=10.087\right.$, One Way Analysis of Variance test). Even though no significant changes were observed in GFAP expression levels in the $D$ region, this signal was increased in the $C$ and $V$ regions $\left(P=0.023, F_{5,29}=3.217\right.$, One Way Analysis of Variance test). S100 expression was also analyzed in the spinal cord of Wnt1Cre2:Rosa26Tom mice, with an overall enhanced immunofluorescence intensity (Figure 4 . B) $\left(\mathrm{P}=0.044, t_{12.98}=-2.224\right.$, Welch's $t$-test $)$. These data suggest that Nic 10 induced a stress-like response probably through astrocyte differentiation likely due to over-activation of nAChRs caused by high-dose nicotine [37; 38].

A

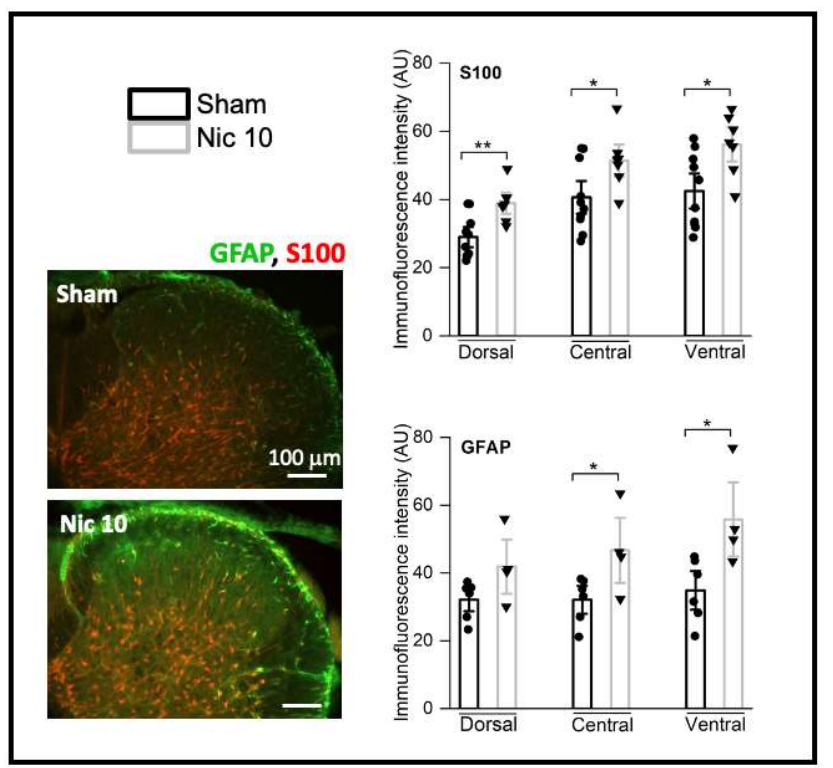

B

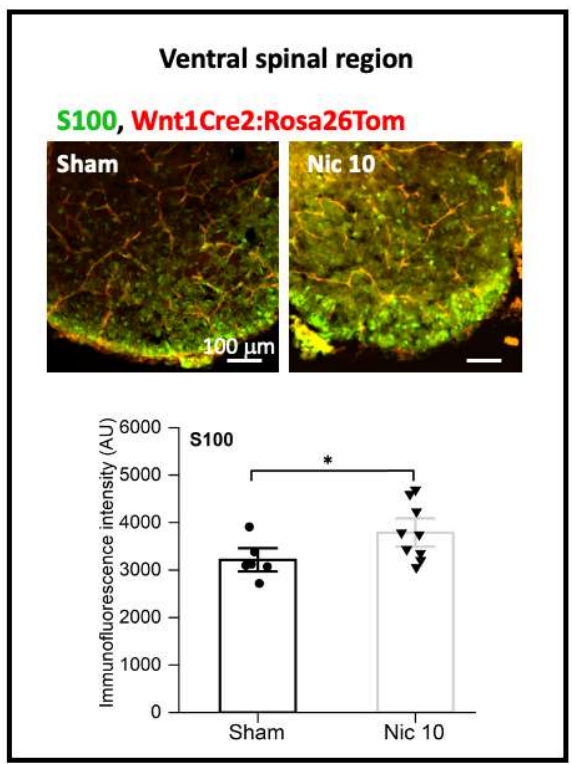

Figure 4. Glial effects by $10 \mu \mathrm{M}$ Nicotine. (A) in the D, C and V regions of the rat spinal cord of rats S100 expression was raised (sham: $\mathrm{n}=10$ and Nic 10: $\mathrm{n}=7 ; \mathrm{D}: \mathrm{P}=0.004, t_{14.08}=-3.464 ; \mathrm{C}: \mathrm{P}=0.03, t_{14.464}=-2.404 ; \mathrm{V}: \mathrm{P}=0.013, t_{14.486}=-2.843$; Welch's $t$ test) and similar rise was observed with GFAP, (sham: $\mathrm{n}=6$ and Nic 10: $\mathrm{n}=4 ; \mathrm{D}: \mathrm{P}=0.09, t_{8}=-1.907 ; \mathrm{C}: \mathrm{P}=$ $0.04, t_{8}=-2.385 ; \mathrm{V}: \mathrm{P}=0.02, t_{8}=-2.795$; Welch's $t$ test) biomarkers. (B) Similar over-expression of S100 was observed in the ventral spinal cord of mice $\left(P=0.044, t_{12.983}=-2.224\right.$, Welch's $t$ test $)$. Scale bar $(100 \mu m)$ applies to all panels.

\section{Nic 10}

2.4. Impaired monosynaptic transmission and fictive locomotion induced by

After treatment with Nic 10, synaptic transmission was recorded $24 \mathrm{~h}$ later from VRs of the rat lumbar spinal cord and compared with that of sham preparations. Monosynaptic transmission (Figure 5. A) was substantially impaired after incubation with nicotine ( $\mathrm{P}=<0.001, \mathrm{U}=0$, Mann-Whitney test); however, the polysynaptic reflex was not significantly depressed (Figure 5. B; amplitude: $\mathrm{P}=0.445, \mathrm{U}=65$; area: $\mathrm{P}=0.617, \mathrm{U}=$ 70; Mann-Whitney test). 


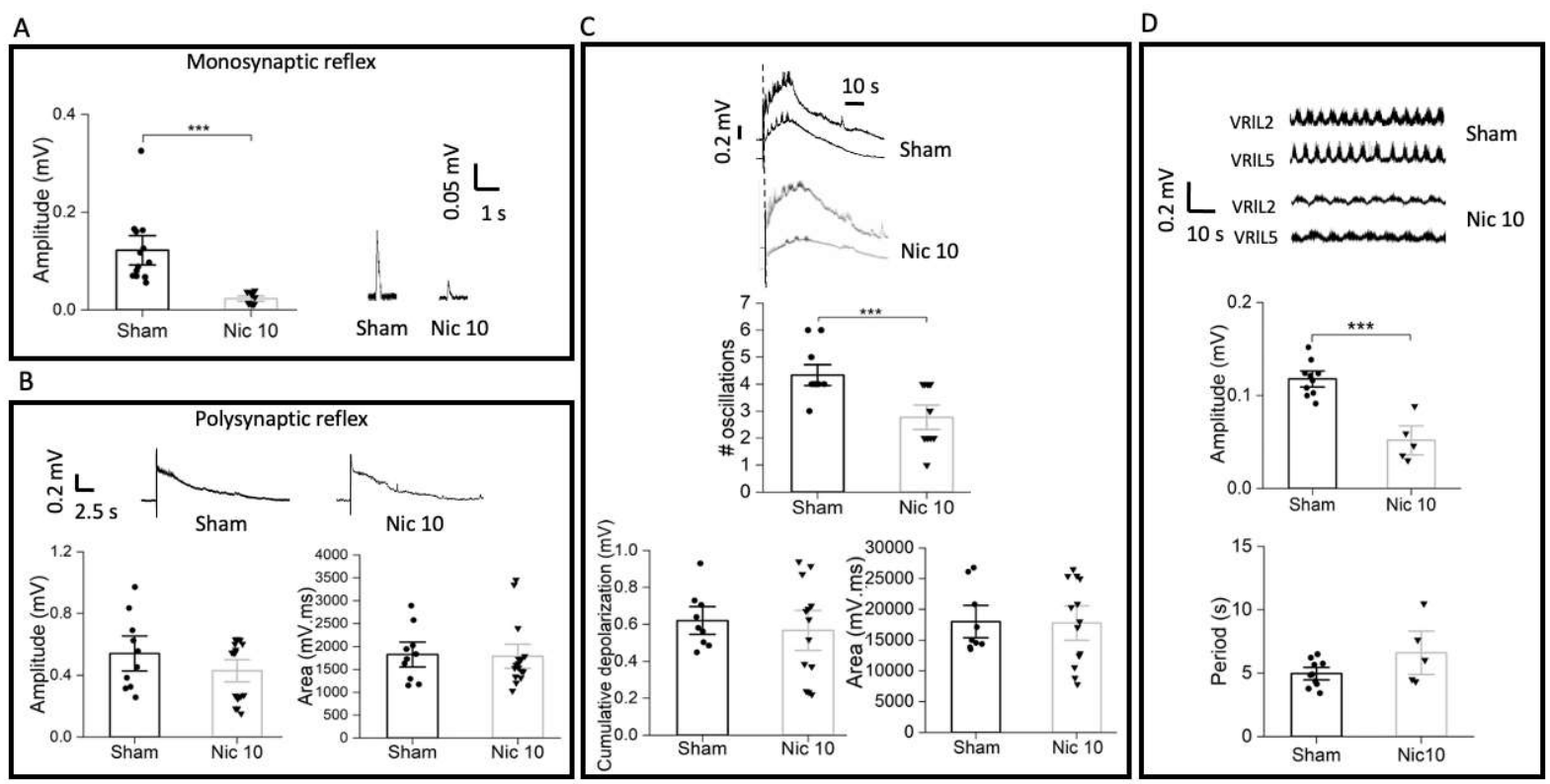

Figure 5. Limited/impaired synaptic transmission and fictive locomotion after Nic $10(n=5)$ in the rat spinal cord. $(A$, B) Nic 10 abolished monosynaptic reflexes (sham vs Nic $10-\mathrm{P}=<0.001, \mathrm{U}=0$, Mann-Whitney test) whereas polysynaptic reflexes were not significantly affected in comparison to sham $(n=10)$ (sham vs Nic $10-$ Amplitude: $P=0.445$, $U=65$; Area: $\mathrm{P}=0.617, \mathrm{U}=70$, Mann-Whitney test). $(\mathrm{C}, \mathrm{D}) \mathrm{DR}$ evoked oscillations (number of oscillations: $\mathrm{P}=<0.001, t_{22.66}=$ 3.943, Welch's $t$ test), their amplitude and period were significantly decreased by Nic 10 (amplitude: $\mathrm{P}=0.001, t 6.588=$ 5.548; period: $\mathrm{P}=0.09, t_{13}=-1.801$; Welch's $t$ test) with no change in cumulative depolarization amplitude or area.

Pulse trains applied to a single lumbar dorsal root (DR) are known to evoke segmentally alternating oscillations on top of the cumulative depolarization observed on VRs. These oscillations have the hallmarks of electrically induced fictive locomotion [39] and their number was significantly reduced after treatment with $\mathrm{Nic} 10\left(\mathrm{P}=<0.001, t_{22.66}\right.$ $=3.943$, Welch's $t$ test) (Figure 5. C), while no depression was observed for the cumulative depolarization amplitude $\left(P=0.551, t_{19.56}=0.607\right.$, Welch's $t$ test $)$ or its area $(P=0.929$, $t_{19.604}=0.0904$, Welch 's $t$ test) (Figure 5. C). Fictive locomotor patterns alternating among flexor and extensor motor pools were also elicited by bath-applied drugs like NMDA plus 5HT [40]. In the present study, Nic 10 significantly decreased the cycle amplitude of the chemically induced fictive locomotion, while no changes in the cycle periodicity (amplitude: $\mathrm{P}=0.001, t_{6.588}=5.548$; period: $\mathrm{P}=0.09, t_{13}=-1.801$; Welch's $t$ test) (Figure $\left.5 . \mathrm{D}\right)$.

\subsection{Effect of nicotine $(10 \mu \mathrm{M})$ on dorsal-dorsal root potential}

To further investigate whether Nic 10 was able to affect the functionality of rat dorsal horn neurons, the dorsal-dorsal root potentials (D-DRPs) were recorded from one DR following stimulation of an adjacent ipsilateral DR in sham or Nic 10 conditions (Supplemental Figure 2. A). Despite the slightly smaller average amplitude of this response after Nic 10, there was no significant difference with the sham control, which is consistent with our previous results suggesting that there was no loss of dorsal horn neurons $(\mathrm{P}=$ 0.106, $\mathrm{U}=83$, Mann-Whitney test). 
2.6. Neuronal number, motoneurons and Wnt1 pathway after excitotoxic insult followed by Nic 10

As expected, application of KA $(50 \mu \mathrm{M} ; 1 \mathrm{~h})$ induced excitotoxicity causing $24 \mathrm{~h}$ later substantial neuronal death (NeuN+ neurons; $\mathrm{P}=<0.001, \mathrm{~F}_{8,80}=159.745$, One Way Analysis of Variance test) in the $\mathrm{D}\left(\mathrm{P}=<0.001, t_{15.2}=9.337\right.$, Welch's $t$ test $), \mathrm{C}(\mathrm{P}=<0.001$, $t_{14.36}=4.327$, Welch's $t$ test $)$ and $\mathrm{V}\left(\mathrm{P}=<0.001, t_{15.70}=8.307\right.$, Welch's $t$ test $)$ regions of the rat spinal cord. Interestingly, Nic 10 prevented the fall in neuronal numbers evoked by KA in the $\mathrm{D}$ region (KA vs KA+Nic/Nic 4 h: $\mathrm{P}<0.001, t_{15.03}=-10.21$, Welch's $t$ test); however, Nic 10 was unable to counteract excitotoxic damage in spinal regions C and V (Figure 6. A, upper panel histogram). The D-DRPs, that were abolished by KA, persisted one day later when Nic 10 was applied together with KA followed by Nic 10 for $4 \mathrm{~h}$ (KA+Nic/Nic 4h; Supplemental Figure 2. B) $\left(P=<0.001, \mathrm{H}_{(2)}=30.156\right.$, Kruskal-Wallis One Way Analysis of Variance on Ranks test).

A

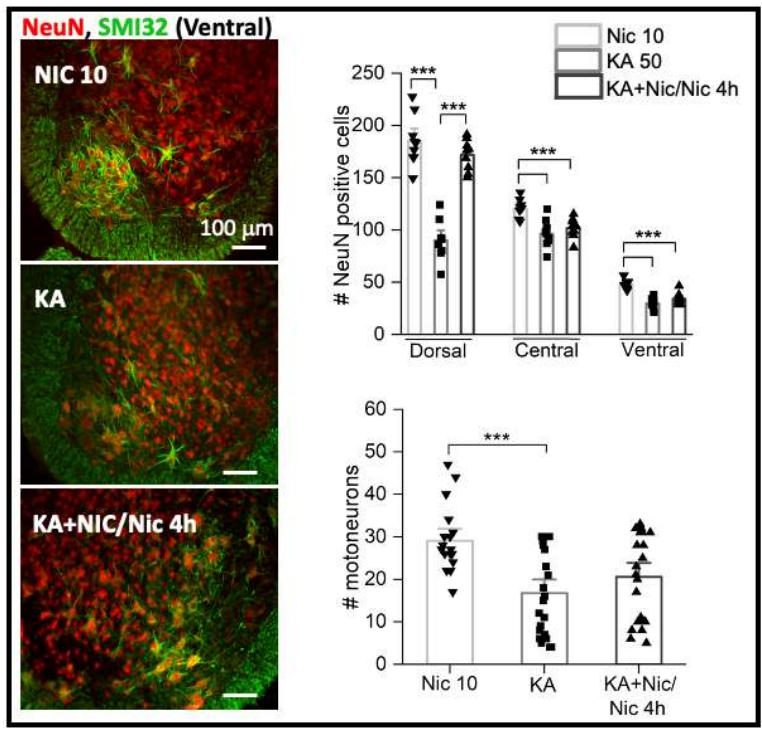

$B$

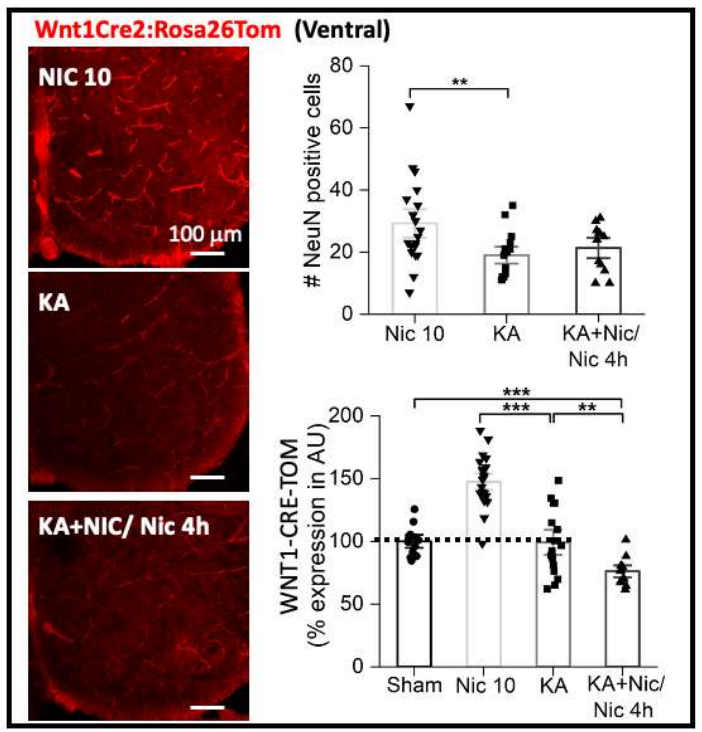

Figure 6. Neuronal number and Wnt1activity after KA application alone or with the co-application protocol KA+Nic 10 followed by Nic 10 for $4 \mathrm{~h}$ (KA+Nic/Nic 4h). (A) KA administration caused fall in neuronal (NeuN red in the example images; Nic: $\mathrm{n}=3$, KA: $\mathrm{n}=3, \mathrm{KA}+\mathrm{Nic} / \mathrm{Nic} 4 \mathrm{~h}: \mathrm{n}=3$ ) (Nic 10 vs KA: $\mathrm{P}=<0.001, t_{15.228}=9.337$, Welch's $t$ test) and motoneuronal (SMI32 green; Nic 10: $\mathrm{n}=6, \mathrm{KA}: \mathrm{n}=7, \mathrm{KA}+\mathrm{Nic} / \mathrm{Nic} 4 \mathrm{~h}: \mathrm{n}=7$ ) (Nic 10 vs KA: $\mathrm{P}=<0.001, t_{37.95}=4.361$, Welch's $t$ test) numbers while Nic 10 application together with KA preserved neurons in the dorsal horn (KA vs $\mathrm{KA}+\mathrm{Nic} / \mathrm{Nic} 4 \mathrm{~h}: \mathrm{P}=<0.001, t_{15.03}=-10.21$, Welch's $t$ test) with no improvement in the C (KA vs KA+Nic/Nic 4 h: $\mathrm{P}=0.35$, $t_{14.39}=-0.974$, Welch's $t$ test) and V (KA vs KA+Nic/Nic 4 h: $\mathrm{P}=0.1, t_{15.8}=-1.73$, Welch's $t$ test) region in the rat spinal cord. No recovery in motoneuronal numbers were observed after $\mathrm{KA}+\mathrm{Nic} / \mathrm{Nic} 4 \mathrm{~h}\left(\mathrm{KA}\right.$ vs $\mathrm{KA}+\mathrm{Nic} / \mathrm{Nic} 4 \mathrm{~h}: \mathrm{P}=0.2, t_{41.96}=$ -1.248, Welch's $t$ test) in the rat spinal cord. (B) In the mouse spinal cord, KA (KA: $n=4$; Nic 10: $n=5)$ alone significantly diminished neurons in the ventral horn (KA vs Nic $10: \mathrm{P}=0.007, t_{30.05}=2.887$, Welch's $t$ test) with no recovery observed after $\mathrm{KA}+\mathrm{Nic} / \mathrm{Nic} 4 \mathrm{~h}(\mathrm{n}=3)\left(\mathrm{KA}\right.$ vs $\mathrm{KA}+\mathrm{Nic} / \mathrm{Nic} 4 \mathrm{~h}: \mathrm{P}=0.42, t_{26}=-0.83$, Welch's $t$ test $)$ treatment. KA application did not change the \% Wnt1 expression level in comparison to sham (sham vs KA: P = 0.910, t22.052=0.114, Welch's $t$ test) which is shown by a black dotted line (as 100\%) in the bar plot (lower panel). However, Nic 10 application together with KA significantly reduced the \% Wnt expression (KA vs KA+Nic/Nic 4h: $\mathrm{P}=0.005, t_{21.2}=3.13$, Welch's $t$ test). Minimum 3-4 slices $(\mathrm{N})$ were analyzed per spinal cord. Scale bar $(100 \mu \mathrm{m})$ applies to all panels.

The same Nic 10 dose could not protect ventrally located neurons/motoneurons, when applied together with KA followed by nicotine for another $4 \mathrm{~h}$ (Figure 6. A, lower panel histogram; KA vs KA+Nic/Nic 4h: $\mathrm{P}=0.2, t_{41.96}=-1.248$, Welch's $t$ test). Similar results were obtained with Wnt1Cre2:Rosa26Tom mouse preparations by applying 
nicotine $(10 \mu \mathrm{M})$ together with $\mathrm{KA}$, followed by nicotine (4 h) (Figure 6. B, upper panel; $\mathrm{KA}$ vs $\mathrm{KA}+\mathrm{Nic} / \mathrm{Nic} 4 \mathrm{~h}: \mathrm{P}=0.42, t_{26}=-0.83$, Welch's $t$ test) as nicotine could not alter the ventral neuronal loss elicited by KA.

The administration of KA alone did not induce changes in Wnt1 signal compared to sham (Figure 6. B, lower panel; sham vs KA: $\mathrm{P}=0.910, t_{22.052}=0.114$, Welch's $t$ test). This suggests that KA could not modulate the activation of the Wnt1 promoter in the ventral spinal cord. Nevertheless, application of Nic 10 together with KA resulted in an overall reduction in Wnt1 signal (Figure 6. B, lower panel; KA vs KA+Nic/Nic 4h: $\mathrm{P}=0.005, t_{21.2}=$ 3.13; sham vs KA+Nic/Nic 4h: $\mathrm{P}=<0.001, t_{21.857}=5.073$, Welch's $t$ test $)$. Such decrease in the expression of the reporter gene reached similar level to the one found when applying the Wnts pathway inhibitor irinotecan (see Figure 2. C), suggesting a likely inhibition of the Wnts signaling pathway by Nic 10 . To further explore any relation between nicotine toxicity, Wnts pathway and excitotoxicity, we counted the global number of pyknotic cells as a reliable index of global cell death in our model [4]. Thus, in the ventral region, KA significantly increased the occurrence of pyknotic nuclei (observed with DAPI staining, Supplemental Figure 3. A, B; sham vs KA: $\mathrm{P}<=0.001, t_{15.31}=-10.629$, Welch's $t$ test), a process already detectable at the end of $1 \mathrm{~h}$ application of KA and only slightly less intense after KA+Nic 10 followed by Nic 10 for $4 \mathrm{~h}$ (KA vs KA+Nic/Nic $4 \mathrm{~h}: \mathrm{P}=0.003, t_{29.975}=$ 3.195, Welch's $t$ test). In keeping with data shown in Fig. 2, 3 Nic 10 administration evoked a significant rise in the number of pyknotic nuclei (sham vs Nic 10: $\mathrm{P}=0.03$, t8.15= -2.61, Welch's $t$ test). After application of irinotecan (Supplemental Fig. 3 B), the number of pyknotic cells was similar to the one of untreated controls, indicating that in basal conditions Wnts pathway activity was not constitutively operating to support cell survival in vitro whereas nicotine administration together with irinotecan drastically increased the number of pyknotic cells (sham vs Irinotecan+Nic $10: \mathrm{P}=<0.001, t_{18.37}=-9.58$; Irinotecan vs Irinotecan+Nic $10: \mathrm{P}=<0.001, t_{18.496}=-9.435$, Welch's $t$ test).

\subsection{Poor recovery in reflex responses and fictive locomotion}

The monosynaptic reflex amplitude was equally depressed $24 \mathrm{~h}$ after Nic alone (cf. Fig. 5 A), KA or Nic 10 after KA followed by nicotine (4 h) (Figure 7. A; P = 0.2, $\mathrm{H}_{(2)}=3.108$, Kruskal-Wallis One Way Analysis of Variance on Ranks test). Conversely, polysynaptic reflexes were partly improved (in amplitude and area) after the combined treatment with Nic 10 and KA vs KA alone (Figure 7. B; amplitude: $\mathrm{P}=<0.001, \mathrm{~F}_{2,56}=32.99$; area: $\mathrm{P}=$ $<0.001, F_{2,55}=57.15$; One Way Analysis of Variance test). Both electrically and chemically induced fictive locomotor patterns were completely abolished by KA. The standard protocol of Nic 10 plus KA compared with KA alone did not improve any component of the DR-induced response including cumulative depolarization and oscillations (Figure 7. C; number of oscillations: $\mathrm{P}=<0.001, \mathrm{~F}_{2,33}=51.9$; cumulative depolarization: $\mathrm{P}=<0.001, \mathrm{~F}_{2,40}=$ 21.1; area: $\mathrm{P}=<0.001, \mathrm{~F}_{2,40}=31.26$; One Way Analysis of Variance test). Nonetheless, in the case of chemically induced fictive locomotion, low amplitude slow oscillations were observed after such a protocol (Figure 7. D; amplitude: $\mathrm{P}=<0.001, \mathrm{H}_{(2)}=15.262$; period: $\mathrm{P}$ $=<0.001, \mathrm{H}_{(2)}=14.563 ;$ Kruskal-Wallis One Way Analysis of Variance on Ranks test). 

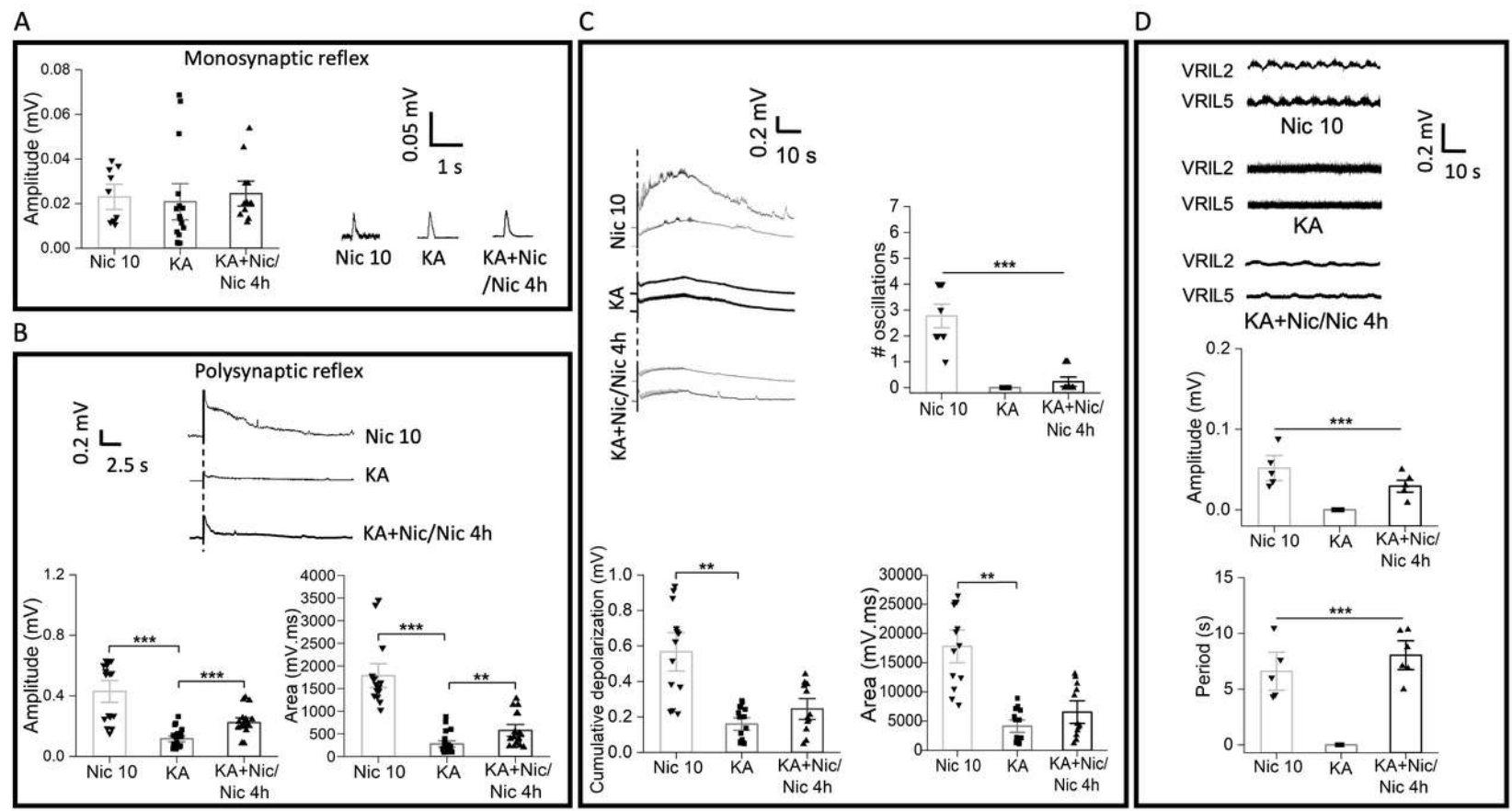

Figure 7. Synaptic transmission and fictive locomotion after excitotoxic insult by KA ( $\mathrm{n}=8$ ) or treatment with coapplication of KA+Nic 10 followed by Nic 10 for $4 \mathrm{~h}(\mathrm{KA}+\mathrm{Nic} / \mathrm{Nic} 4 \mathrm{~h}, \mathrm{n}=6)$ in the rat spinal cord. (A) Monosynaptic reflex responses were suppressed by Nic $10(n=5)$ which were similar to the responses evoked by KA with no further improvement after $\mathrm{KA}+\mathrm{Nic} / \mathrm{Nic}$ 4h application $\left(\mathrm{P}=0.2, \mathrm{H}_{(2)}=3.108\right.$, Kruskal-Wallis One Way Analysis of Variance on Ranks test). (B) Polysynaptic reflex responses diminished by KA (Nic 10 vs KA; amplitude: $\mathrm{P}=<0.001, t_{17.052}=6.34$, Welch's $t$ test; area: $\mathrm{P}=<0.001, t_{17.1}=8.350$; Welch's $t$ test) were partly recovered by Nic 10 when co-applied with KA (KA vs KA+Nic/Nic 4h; amplitude: $\mathrm{P}=<0.001, t_{28.34}=-4.372$; area: $\mathrm{P}=0.006, t_{24.58}=-3.013$; Welch's $t$ test). (C) Electrically induced fictive locomotion blocked by KA (Nic 10 vs KA; number of oscillations: $\mathrm{P}=<0.001$, $t_{12}=9.144$; cumulative depolarization: $\mathrm{P}=<0.001, t_{14.51}=5.38$; area: $\mathrm{P}=<0.001, t_{15.41}=6.83$; Welch's $t$ test) was not recovered after Nic 10 coadministration. (D) Chemically induced fictive locomotion disrupted by KA (amplitude: $\mathrm{P}=0.002, \mathrm{U}=0$; period: $\mathrm{P}=$ 0.002, $\mathrm{U}=0$; Mann-Whitney test) was very mildly recovered after Nic 10 co-application with KA followed by Nic $4 \mathrm{~h}$ (KA vs KA+Nic/Nic 4h; amplitude: $\mathrm{P}=<0.001, \mathrm{U}=0$; period: $\mathrm{P}=<0.001, \mathrm{U}=0$; Mann-Whitney test).

\section{Discussion}

\subsection{An evolving scenario from neuroprotection to neurotoxicity}

The key finding of this study is that nicotine induced neurotoxicity in the spinal neuronal network of newborn rodents, and that there was a fine dividing line between neuroprotective $(1 \mu \mathrm{M})[2]$ and neurotoxic $(10 \mu \mathrm{M})$ doses of this drug. Both effects were associated with various degrees of motor pool depolarization which lingered for several minutes. After $10 \mu \mathrm{M}$ nicotine, intense motoneuron firing appeared and was, $24 \mathrm{~h}$ later, followed by neuronal loss in the central and ventral areas of the spinal cord. This phenomenon had the main characteristics of excitotoxicity which had replaced the neuroprotective action earlier reported [2]. The onset of nicotine toxicity occurred in parallel with a reduction in the ability of nicotine to activate the Wnt1 signaling pathway in the spinal cord. In fact, our genetic model to induce Tomato gene expression in the spinal cord by crossing Wnt1-Cre with Rosa26-Tom mice allowed us to monitor functional changes resulting from the activation of Wnt1 mediated by different nicotine concentrations. While low doses of nicotine led to increased number of surviving neurons in spinal slices and raised Wnt1 activity, neurotoxicity was accompanied by lower Wnt1 
activity. These observations imply that neuronal resilience and Wnt1 stimulation proceeded in parallel, although there was no implicit suggestion of causality between these two events because it is not known whether a few surviving neurons strongly expressed Wnt1 or a larger number of neurons moderately activated Wnt1. Indeed, the correlation between localization of Wnt1 activity and neurons was weak, indicating a range of potential interpretations like nicotine-evoked release of unidentified neuronal messengers stimulating Wnt1 in non-neuronal cells, release of other Wnt proteins by neurons to affect Wnt1 expressing cells, or nicotine desensitization occurring preferentially at certain cholinergic receptors. These notions remain currently conjectural and will require future investigation. Nevertheless, pharmacological inhibition of Wnt signaling by irinotecan $[33 ; 34]$ largely increased the extent of neuronal pyknosis, a marker of cell death, thus a role of this pathway.

Notwithstanding elucidation of these issues, it was apparent that nicotine toxicity strongly depressed monosynaptic transmission on motoneurons while displaying much less depression of polysynaptic transmission and cumulative depolarization evoked by repeated DR stimuli. The preferential inhibition of monosynaptic reflexes suggests an effect targeted at presynaptic level of transmitter release [41] which could be, at least partly, overcome by stronger afferent fiber stimulation and consequently stronger release typically observed with polysynaptic reflexes. It was, however, clear that perturbation by nicotine $(10 \mu \mathrm{M})$ of premotor networks led to disruption of fictive locomotion which is a highly integrated function necessitating complex, concerted activity at the level of the central pattern generator $[35 ; 36 ; 42]$. Thus, chemically-driven fictive locomotion that requires broad recruitment of locomotor circuits by bath-applied drugs was depressed whereas electrically-induced fictive locomotion that is based on a more segmental recruitment was actually suppressed. We propose that strong excitation of motor networks by Nic 10 was the initial step to produce synaptic depression and cell death.

Previous studies have clearly demonstrated how prenatal or postnatal exposure to nicotine leads to disruption of synaptic transmission within brainstem respiratory motor networks by altering GABAergic [43], glycinergic [44] and glutamatergic [45] transmission. Our present data are consistent with a damaging effect of nicotine on postnatal motor networks even in the spinal cord as long as a critical drug concentration is reached.

\subsection{Nicotine, Wnt signaling and neurotoxicity}

A number of former studies have indicated crosstalk between nicotine and the Wnt signaling pathway. For example, nicotine has been shown to prevent P19 cell differentiation into cardiomyocytes [46], and to induce epithelial-mesenchymal transition [47] and lung cancer [48] via overexpression of the Wnt signaling pathway. In response to stress caused by smoking, a suppression of the $\mathrm{Wnt} / \beta$-catenin pathway has been reported in the airway epithelium [49]. Our present data also support a functional dialogue between Wnt1 and nicotine as low levels of nicotine $(0.5 \mu \mathrm{M})$ caused marked increase in Wnt1 activation in parallel with significant neuroprotection. Indeed, the expression of the Wnt1 signal at the ventral spinal cord region was mostly colocalized with S100 signal, a calcium-binding protein mainly expressed by challenged glia [50]. Additionally, upregulation of Wnt 1 and $\beta$-catenin and attenuation of inducible nitric oxide synthase (iNOS) expression can be associated with neuroprotection in a mouse model of Parkinson's disease [51].

Several research groups linked Wnt signaling pathways to the inflammatory response that activates astrocytes [27; 52], dendritic remodelling after chronic pain models [53] 
and even neurogenesis in the developing spinal cord [54]. Here, treatment with high dose nicotine caused astroglia activation by the overexpression of GFAP and S100 perhaps indicative of accelerated maturation of astrocytes due to activation of nAChRs [38]. It seems, therefore, likely that astrocytes reacted to the nicotine challenge and contributed to stimulate Wnt1 activity whose reporter gene was relatively well correlated to the glial biomarker S100, typically enhanced after damage of various origin [50].

Although nicotine shows neurotoxic effects on spinal neurons (central and ventral region) and motoneurons, it produced minimal toxicity to dorsal horn neurons, probably due to the high density of neurons [55] and their neuronal nAChRs [56; 57; 58], which can evoke potent upregulation of inhibitory synaptic activity in the dorsal horn [58] with likely downregulation of overexcitation and consequent damage limitation.

\subsection{Effect of high nicotine on kainate-mediated excitotoxicity}

KA was previously used in our laboratory as an excitotoxic agent to induce experimental SCI in a newborn rodent model in vitro that allows monitoring early pathophysiological events for up to $24 \mathrm{~h}[59 ; 60]$. In particular, transient $(1 \mathrm{~h}) \mathrm{KA}(50 \mu \mathrm{M})$ incubation was shown to abolish fictive locomotor patterns irreversibly and, thereby, provides a model with slowly developing damage and relatively delayed outcome in terms of network structure and function [2; 59]. In the present report nicotine $(10 \mu \mathrm{M})$ co-applied with KA provided significant histological preservation of neurons only in the dorsal horn. At the same time, Nic 10 treatment did not protect central and ventral horn neurons against KA excitotoxicity. Interestingly, even when KA and nicotine were coapplied and the physiological outcome was very poor, a substantial number of neurons was histologically intact. This observation accords with our former results that have indicated a ceiling to excitotoxic damage [59] in line with clinical SCI damage which is rarely total. Nonetheless, despite surviving neurons in large numbers, complex network activities like fictive locomotion collapsed because the network membership of the central pattern generator presumably fell below a critical value whereby coordinated activity becomes impossible [61].

Since KA did not affect the level of the Wnt1-dependent gene expression, the present data indicate that toxicity induced by a glutamate agonist or a cholinergic agonist involved distinct cellular processes even if they were not additive.

\section{Materials and Methods}

\subsection{Wild-type rat spinal cord preparation}

In vitro spinal cord preparations were obtained from postnatal (P0-P2) wild-type Wistar rats (total $n=115$, where $n$ is the total number of rats used in the study) after decapitation under urethane anesthesia ( $0.2 \mathrm{ml}$ i.p. of a $10 \% \mathrm{w} / \mathrm{v}$ solution). Whole spinal cord preparations were gently removed in oxygenated Krebs solution (in mM; $113 \mathrm{NaCl}, 4.5$ $\mathrm{KCl}, 1 \mathrm{MgCl} 2.7 \mathrm{H} 2 \mathrm{O}, 2 \mathrm{CaCl}$, $1 \mathrm{NaH} 2 \mathrm{PO} 4,25 \mathrm{NaHCO}$, 11 glucose; gassed with 95\% oxygen and 5\% CO2; pH 7.4 at room temperature, flowing at $7.5 \mathrm{~mL} / \mathrm{min}$ ) as reported earlier $[2 ; 62 ; 63]$ and were kept in Krebs solution for $2 \mathrm{~h}$ to reach functional recovery.

\subsection{Transgenic mice spinal cord preparation}

Wnt1Cre2 mice (Jackson stock № 022501) were mated with Rosa26-tdTomato mice (Rosa26Tom; Jackson stock № 007909). In mouse genetic lineage tracing strategies, two 
strains of transgenic mice are mated. One of them carries a transgene that allows the expression of the Cre recombinase enzyme (Cre) under a specific promoter (in this case, Wnt1). The other strain contains two loxP sites flanking a STOP signal, before a reporter gene sequence (in this case, Tomato), under a ubiquitously active promoter (Rosa26). When both transgenes recombine in F1, Cre cleaves the loxP sites and removes the STOP signal, so that only in cells in which Wnt1 was activated at some point in development is the reporter gene expressed. Genotyping of Wnt1-Cre2 transgenic mice was performed by PCR with primers (5'-ARRCTCCCACCGTCAGTACG3') and (5'-CGTTTTCTGAGCATACCTGCA 3') giving a 400 bp product [64]. Wnt1Cre2:Rosa26Tom mice were mated with other Wnt1Cre2:Rosa26Tom animals. The penetration and recombination of both transgenes was assessed by direct observation of tail tip under fluorescent microscope (Supplemental Figure 1A). Only tissues that showed Tomato expression were included and were randomly distributed among the experimental groups. Thoracolumbar spinal cord preparations were isolated from postnatal Wnt1Cre2:Rosa26Tom mice (1-3 days old) in accordance with standard procedures [59]. Protocols to maintain mouse spinal preparations were similar to those for the rat one. Thereafter, spinal cord tissue was immediately fixed in $1 \times$ phosphate-buffered saline (1X PBS) containing $4 \%$ paraformaldehyde (PFA; $24 \mathrm{~h}$ at $4^{\circ} \mathrm{C}$ ) followed by $30 \%$ sucrose $1 \times$ PBS for cryoprotection $(24 \mathrm{~h}$ at $4^{\circ} \mathrm{C}$ ). After immunostaining, images were taken at a $20 \mathrm{x}$ magnification using a Nikon Eclypse NiE microscope (Melville, NY, USA). Since the staining was diffuse, data quantification of Tom expression was performed in terms of immunofluorescence intensity (expressed in arbitrary units, AU) by the ImageJ software (NIH, https://imagej.nih.gov/ij/index.html) in a 150X150 $\mu \mathrm{m}$ area. To measure the colocalization between Wnt1Cre2:Rosa26Tom, NeuN and S100 signals were analyzed at the ventral spinal cord region by Pearson's correlation were calculated using Colocalization Threshold plugin (NIH, https://imagej.nih.gov/ij/index.html). The method was implemented in Costes et al. (2004) [32] using the methodology as reported by Dunn et al. (2011) [31] (Supplemental Figure 1 B).

\subsection{Protocol for drug application and lesioning the spinal cord}

Nicotine ( $4 \mathrm{~h}$ application) was used at $0.5-10 \mu \mathrm{M}$ concentration, the latter previously found to protect brainstem hypoglossal motoneurons from excitotoxic death [1]. It was applied alone or in combination with excitotoxic conditions: data were compared with results from untreated spinal cords maintained in vitro for $24 \mathrm{~h}$ and designated as sham.

KA (50 $\mu \mathrm{M}, 1 \mathrm{~h}$ application) was used to induce an excitotoxic lesion primarily affecting the gray matter $[4 ; 59]$, which fully blocks fictive locomotor patterns (evoked either chemically or electrically) for at least $24 \mathrm{~h}$. To investigate the effect of nicotine neuroprotection on spinal locomotor networks, nicotine $(10 \mu \mathrm{M})$ was applied together with KA (for $1 \mathrm{~h}$ ) followed by nicotine alone for $4 \mathrm{~h}$ (represented as $\mathrm{KA}+\mathrm{Nic} / \mathrm{Nic} 4 \mathrm{~h}$ ).

In order to compare the dose dependent effect of nicotine on network depolarization (measured from the baseline DC level) various nicotine concentrations were used such as $0.5,1,2,10 \mu \mathrm{M}$ on day 1 (for $4 \mathrm{~h}$ ). Changes in DC polarization of any VR represented the summated output of motoneuron population depolarization produced by direct action on such cells plus indirect excitation from pre-motoneurons. After leaving preparations overnight in Krebs solution, reflex activities (mono- and poly-synaptic) and fictive locomotion were tested on the next day as previously reported [4;59].

For Wnt1Cre2:Rosa26Tom mouse experiments the total number (n) of mice used was 42. Four experimental groups were used as follows: sham, Nic 4h, KA and KA+Nic/Nic 4 h. 
From animals showing high efficiency of transgene recombination, different spinal cords preparations were subjected to different experimental conditions. Some spinal cords were treated only with irinotecan (Wnt signaling and DNA topoisomerase I inhibitor, 5 $\mu \mathrm{M},[33 ; 34]$ or different doses of nicotine $(0.5,1$ and $10 \mu \mathrm{M})$ and subjected to the same experimental procedures and were processed for immunostaining.

\subsection{Electrophysiology}

Full details of electrophysiological recording were previously reported by Marchetti et al. (2001) [31] and Taccola et al. [4]. Briefly, to investigate the reflex activity and fictive locomotion from the rat spinal cord, VRs of the lumbar (L2 and L5) segments were sucked with tight-fitting suction electrodes to record DC coupled responses from L2 and L5 VRs which mainly carry flexor and extensor motor responses to the hindlimb muscles, respectively [36]. VR signals were evoked by square pulses $(0.1 \mathrm{~ms})$ applied to ipsilateral dorsal roots (DR) using bipolar suction electrodes. DR stimulus intensity was adjusted to induce monosynaptic reflex responses, which was considered equivalent to $1 \mathrm{x}$ threshold [31] and polysynaptic reflex responses when the stimulus was three times higher [65]. The responses were computed by considering 3-5 averaged events for the peak amplitude and area. Previously reported intracellular recordings from spinal motor neurons have confirmed the functional identification of these responses as monosynaptic and polysynaptic reflexes, respectively [66]. D-DRPs were elicited by electrical stimulation of a single lumbar DR and the output signal was recorded from the ipsilateral adjacent DR. To evoke electrically or chemically induced fictive locomotion, a train of 30 pulses at $2 \mathrm{~Hz}$, or bath application of N-methyl-D-aspartate (NMDA; 3-6 $\mu \mathrm{M}$ ) plus 5hydroxytryptamine $(5-\mathrm{HT} ; 10 \mu \mathrm{M})$ were used, respectively [36]. Fictive locomotion was characterized by VR rhythmic cycles alternating between left and right side at segmental level and between flexor (L2) and extensor (L5) VRs on the same side once about every $2-3$ s [36]. For the analysis of cycle peak amplitude and periodicity, 20 consecutive oscillations were considered as reported previously [4]. Data were acquired, digitized and recorded in pClamp 9.2 (Molecular Devices, Sunnyvale, CA, USA) at $20 \mathrm{KHz}$ (acquisition frequency).

\subsection{Immunohistochemistry}

After completing the electrophysiological experiments, spinal cords were fixed in $4 \%$ paraformaldehyde (PFA) overnight and then cryoprotected with $30 \%$ (w/v) sucrose the subsequent day. The whole procedure was performed as reported previously [55; 63; 67; $68 ; 69 ; 70]$. Transverse spinal sections $(30 \mu \mathrm{m})$ were cut using a microtome $\left(\right.$ at $\left.-20{ }^{\circ} \mathrm{C}\right)$ from T13 to L5 segments and collected in 1X phosphate buffer solution (PBS) until further use. Spinal cords were processed using a free-floating immunofluorescence protocol where the sections were again washed using 1X PBS followed by incubation with the blocking solution (5\% fetal bovine serum, FBS or normal goat serum, NGS; $5 \%$ bovine serum albumin, BSA; $0.3 \%$ Triton X-100; $1 \%$ PBS) at room temperature. Later, spinal sections were immunolabelled with primary antibodies such as anti-SMI32 (specific to nonphosphorylated neurofilament-H of spinal cord motoneurons; mouse monoclonal; 1:1000 dilution; Chemicon, Millipore, Milan, Italy; NE1023), anti-NeuN (specific neuronal marker; rabbit polyclonal; 1:250 and 1:500 dilution; Merck Millipore, Milan, Italy; ABN78), anti-GFAP (specific for glial fibrillary acidic protein, GFAP, member of class III protein family of intermediate filament, expressed in astrocytes and some other astroglial cells in the central nervous system; mouse monoclonal; 1:500; Sigma- Aldrich; G3893), anti-S100 (specific for S100 protein which is a part of Ca2+ binding proteins family in astrocytes' nuclei and cytoplasm, rabbit polyclonal; 1:1000 and 1:400 dilution; 
DAKO, Glostrup, Denmark; Z0311) and anti-CD31 (specific for Platelet Endothelial Cell Adhesion Molecule-1, mouse monoclonal, Invitrogen, BD Biosciences, Buenos Aires, Argentina; $1: 200$ ) at $4{ }^{\circ} \mathrm{C}$ for overnight. Antibody validation was performed as reported in our previous studies $[2 ; 50]$. On the following day, sections were again washed and immunolabelled with secondary antibodies (1:500 dilution; Life Technologies) such as goat anti-mouse Alexa Fluor 488 (A11029) or 594 (A11032) and goat anti-rabbit Alexa Fluor 488 (A11034) or 594 (A11037) and DAPI (biomarker for cell nuclei; 1:200 dilution used for rat and 1:1000 used for mice; Sigma-Aldrich) for $2 \mathrm{~h}$ at room temperature. Samples were directly viewed with a confocal microscope Leica DM6000, FV300 (Olympus Optical, Tokyo, Japan) or Nis-Eclipse microscope (NIKON, Amsterdam, Netherlands) with $20 \times$ magnification. Images were captured from the dorsal, central (D, C; $350 \times 350$ $\mu \mathrm{m} 2)$ and ventral $(\mathrm{V} ; 300 \times 230 \mu \mathrm{m} 2)$ spinal regions (in the case of Wistar rats) $[2 ; 59 ; 68]$. Data were quantified using ImageJ or Fiji software (https://imagej.net/software/fiji/) In the case of Wnt1-Cre2:Rosa26Tom mice, NeuN positive cells were counted in the ventral region. DAPI nuclear staining was used to identify the dead/dying cells quantified with Fiji software. The average percent values of nuclei with condensed chromatin were compared between all experimental groups for ventral region and normalized to the total number of nuclei. The occurrence of cells with pyknotic nucleus for control condition or after KA application were similar results as previously described for the ventral region [71].

\subsection{Drugs used}

Drugs used in the experiments include nicotine from Sigma Aldrich, kainate from Sigma Aldrich, N-methyl-D-aspartate (NMDA) from Tocris Bioscience (Bristol, UK), 5-hydroxytryptamine (5HT) from Sigma Aldrich, (Saint Louis, MO, USA) and irinotecan from Sibudan (Buenos Aires, Argentina).

\section{7. $\quad$ Statistics}

All the data were statistically analyzed using SigmaPlot 14 and SigmaStat (SigmaStat 3.1, Systat Software, Chicago, IL, USA). Data values were indicated as mean \pm SEM where $n$ represents number of spinal cords used and $\mathrm{N}$ shows number of spinal slices/spinal cord. Normality test was used to differentiate between parametric and non-parametric data. Parametric values were evaluated either by Welch's $t$ test (assuming unequal population variances and/or sample sizes) and non-parametric by Mann-Whitney test. Oneway Analysis of Variance test (ANOVA) was used for multiple comparisons and for non-parametric data Kruskal-Wallis (either Holm Sidak or Dunn) test was applied. The accepted significance level was $\mathrm{P}<0.05$.

\section{Conclusions}

Various efforts have been made to induce neuroprotection of spinal neurons against spinal injury $[68 ; 72 ; 73 ; 74]$. In addition, substantial data are available on nA$\mathrm{ChRs}$ as a potential target to rescue from neurodegeneration using nicotine $[1 ; 2 ; 3]$. However, until now little was known what effect a high concentration of nicotine might have on spinal neuronal networks. The present study shows that exposure to a high level of nicotine could cause neuronal death and upregulate the expression of proteins associated with astrocyte activation. Likewise, our results suggest that changes in the levels of activity of Wnt1, modulated by nicotine were associated with either its neuroprotection or neurotoxicity. Finally, this study highlights the differential vulnerability of the central nervous system of newborn mammals to nicotine exposure, which could 
irreversibly damage a significant number of spinal neurons. Future work is needed to investigate the long-term effects of high doses of nicotine on the postnatal/fetal spinal locomotor circuitry in vivo.

Author Contributions: Conceptualization and design: J.K. and A.N.; data acquisition and analysis: J.K. and G.L.M.; data interpretation: J.K., G.L.M., A.N., J.B.A.; writing: J.K., G.L.M., A.N., J.B.A. All authors approved the manuscript in the current form.

Funding: The work was supported by SISSA intramural grant, CONICET and Regular Associate Scheme of the Abdus Salam International Centre for Theoretical Physics (ICTP).

Institutional Review Board Statement: All the experimentation methods related to postnatal wildtype Wistar rats were authorized by SISSA ethical committee (prot. 3599, 28th May 2012) and were carried out according to the guidelines given by European Union rules for animal experimentation. All efforts were made to minimize the number of animals used and their sufferings to carry out the present project.

Wnt1Cre2:Rosa26Tom transgenic mice were maintained at the Animal Resources Facility (Faculty of Biomedical Sciences, Austral University) in accordance with the guidelines of the of Bioethics at the School of Biomedical Sciences of Austral University and the National Institutes of Health (NIH) guidelines on the ethical use of animals. All efforts were aimed at minimizing animal use and suffering.

Data Availability Statement: Data displayed in this study are available on request from the corresponding author.

Conflicts of Interest: The authors declare no conflict of interest.

\section{Abbreviations}

$\begin{array}{ll}\text { BSA } & \text { Bovine serum albumin } \\ \text { Cre } & \text { Cre recombinase enzyme } \\ \text { D-DRP } & \text { Dorsal-dorsal root potential } \\ \text { DR } & \text { Dorsal root } \\ \text { FBS } & \text { Fetal bovine serum } \\ \text { iNOS } & \text { inducible nitric oxide synthase } \\ \text { KA } & \text { Kainate } \\ \text { L } & \text { Lumbar } \\ \text { n } & \text { total number of rats/mice } \\ \text { N } & \text { number of spinal slices } \\ \text { nAChRs } & \text { nicotinic acetylcholine receptors } \\ \text { Nic } & \text { Nicotine } \\ \text { NGS } & \text { Normal goat serum } \\ \text { NMDA } & \text { N-methyl-D-aspartate (NMDA) } \\ \text { PBS } & \text { Phosphate buffer solution } \\ \text { PFA } & \text { Paraformaldehyde } \\ \text { SCI } & \text { Spinal cord injury } \\ \text { VR } & \text { Ventral root } \\ \text { Wnt } & \text { Wingless related MMTV integration site } \\ \text { 5HT } & \text { 5-hydroxytryptamine }\end{array}$




\section{Supplementary Figures}

A

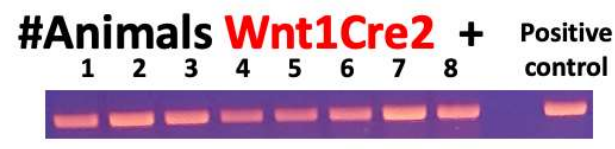

\#Animals Rosa26Tom + Positive

$\begin{array}{lllllllll}1 & 2 & 3 & 4 & 5 & 6 & 7 & 8 & \text { control }\end{array}$

$-\square-\infty-2-$

B

Colocalization map RGB - Wnt1Cre2:Rosa26Tom

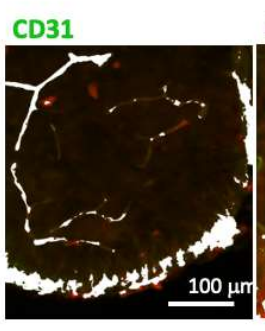

Adult

Wnt1Cre2:Rosa26Tom Wnt1Cre2:Rosa26Tom
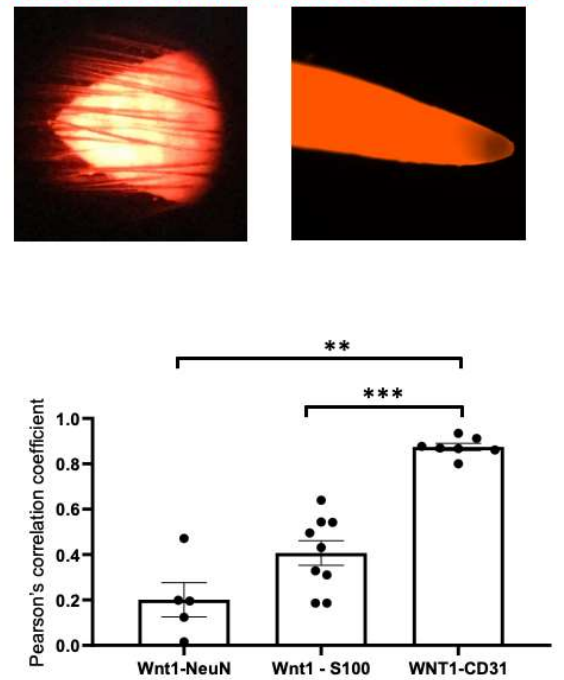

Supplemental Figure 1. (A) Left: bands showing the expression of Cre and Tomato in Wnt1Cre2:Rosa26Tom mouse tail samples by PCR. Right: examples of Wnt1Cre2:Rosa26Tom tail tips of adult and postnatal (P2) mice. (B) Representative binary versions of images of Wnt1Cre2:Rosa26Tom signal with CD31, S100 or NeuN marker. After applying Costes threshold, pixels with positive signals for both are shown in white. Histograms showing a comparison of Pearson's Correlation Coefficient for CD31, S100 or NeuN and Wnt1Cre2:Rosa26Tom: 0.87 $\pm 0.01,0.20 \pm 0.07,0.41 \pm$ 0.05, respectively (S100 vs CD31: P < 0.005; NeuN vs CD31: P < 0.05, U = 10.71; Dunn's Method). Scale bar (100 $\mu \mathrm{m})$ applies to all panels.

A

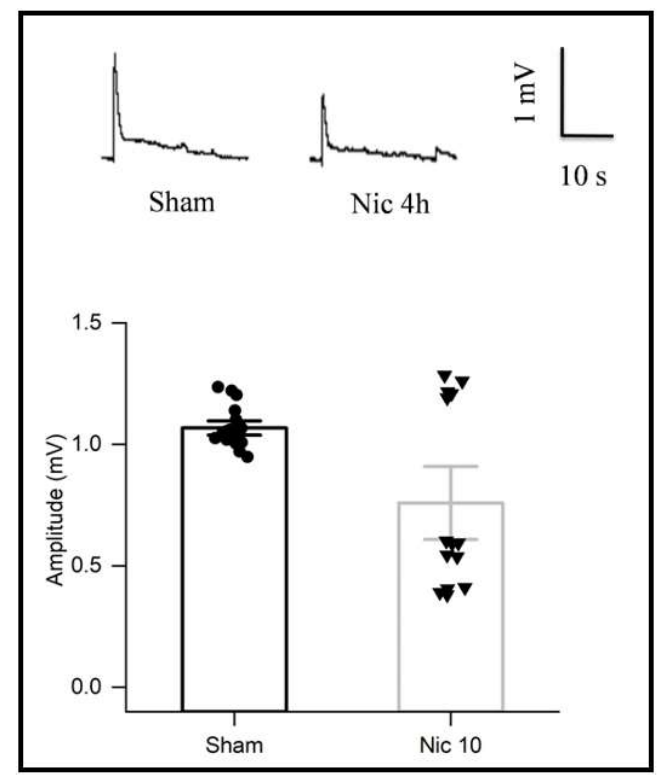

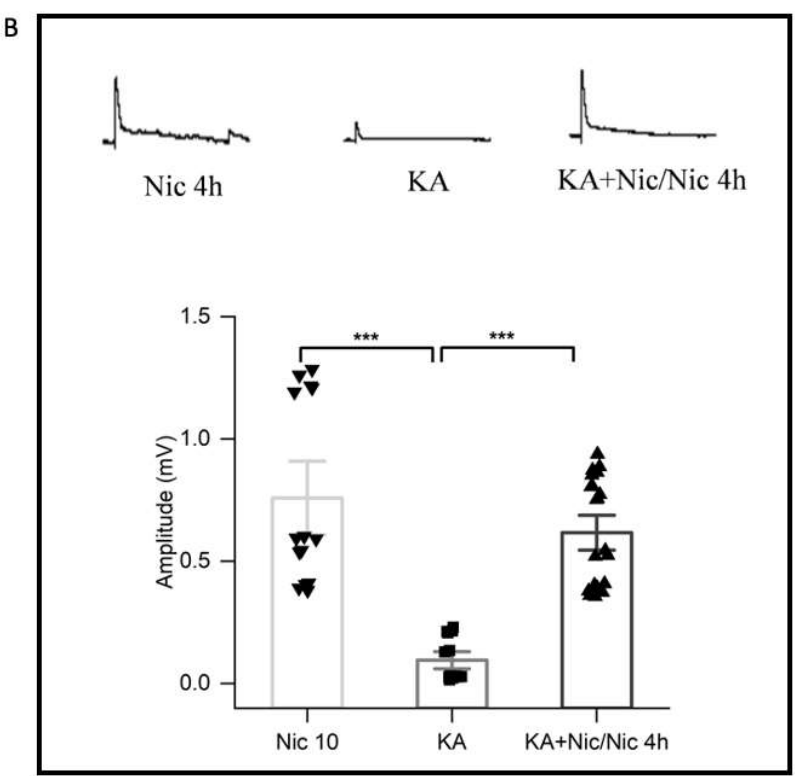

Supplemental Figure 2. D-DRPs recorded from rat lumbar spinal cord. (A) Nic $10(n=3)$ application $(4 \mathrm{~h})$ did not block the amplitude in comparison to sham $(\mathrm{n}=4)$ as indicated in the panel A example and histogram $(\mathrm{P}=0.106, \mathrm{U}=83$, Mann-Whitney test). (B) KA ( $\mathrm{n}=4)$ application drastically reduced the D-DRP amplitude (Nic 10 vs KA: $\mathrm{P}=<0.001, \mathrm{U}=$ 
0, Mann-Whitney) which was recovered to normal after Nic 10 co-application $(\mathrm{n}=5)(\mathrm{Nic} 10 \mathrm{vs} \mathrm{KA+Nic/Nic} 4$ h: $\mathrm{P}=$ $<0.001, \mathrm{U}=0$, Mann-Whitney; $\mathrm{P}=<0.001, \mathrm{H}_{(2)}=30.156$, Kruskal-Wallis One Way Analysis of Variance on Ranks test).

A

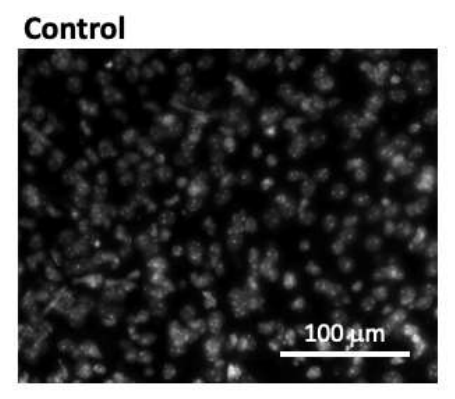

KA

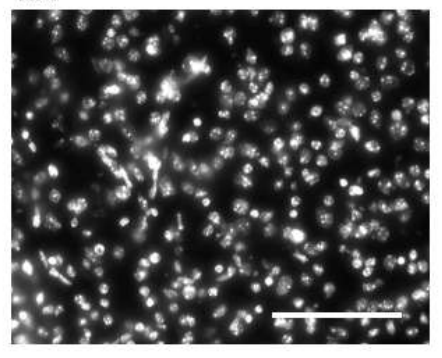

B

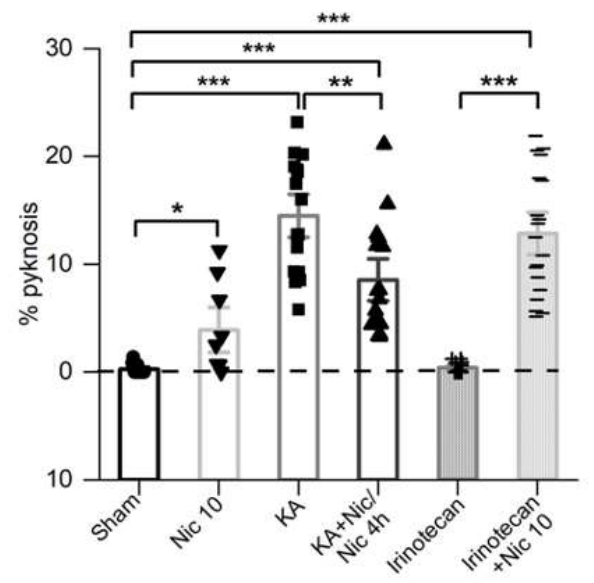

Supplemental Figure 3. Pyknosis evoked by nicotine, KA or irinotecan in the ventral spinal region of mice. (A) Images showing nuclear staining by DAPI in sham and KA treated sections. (B) Histogram showing \% pyknosis evoked by Nic 10 (sham vs Nic 10: $P=0.03$, t8.15 $=-2.616$, Welch's $t$ test), KA (sham vs KA: $P<=0.001, t_{15.31}=-10.629$, Welch's $t$ test) or $\mathrm{KA}+\mathrm{Nic} / \mathrm{Nic} 4 \mathrm{~h}\left(\mathrm{KA}\right.$ vs KA+Nic/Nic 4h: $\mathrm{P}=0.003, t_{29.975}=3.195$, Welch's $t$ test) treatment. Extensive pyknosis was evoked by irinotecan+Nic 10 treatment (sham vs Irinotecan+Nic $10: \mathrm{P}=<0.001, t_{18.4}=-9.58$; Irinotecan vs Irinotecan+Nic 10 : $\mathrm{P}=$ $<0.001, t_{18.496}=-9.435$, Welch's $t$ test). Scale bar $(100 \mu \mathrm{m})$ applies to all panels.

\section{References}

1. Corsini, S., Tortora, M., Rauti, R., Nistri, A. Nicotine protects rat hypoglossal motoneurons from excitotoxic death via downregulation of connexin 36. Cell Death Dis 2017, 8, e2881.

2. Kaur, J., Rauti, R., Nistri, A. Nicotine-mediated neuroprotection of rat spinal networks against excitotoxicity. Eur J Neurosci 2018, 47, 1353-1374.

3. Bajrektarevic, D., Corsini, S., Nistri, A. Tortora, M. Nicotine Neuroprotection of Brain Neurons: The Other Side of Nicotine Addiction in "Neuroscience of Nicotine". Preedy V.R. Ed, Academic Press, London 2019, 79-86.

4. Taccola, G., Margaryan, G., Mladinic, M., \& Nistri, A. Kainate and metabolic perturbation mimicking spinal injury differentially contribute to early damage of locomotor networks in the in vitro neonatal rat spinal cord. Neuroscience 2008, $155,538-555$.

5. Taccola G, Mladinic M, Nistri A. Dynamics of early locomotor network dysfunction following a focal lesion in an in vitro model of spinal injury. Eur J Neurosci 2010, 31, 60-78.

6. Richardson, E. J., Ness, T. J., Redden, D. T., Stewart, C. C., Richards, J. S. Effects of nicotine on spinal cord injury pain vary among subtypes of pain and smoking status: results from a randomized, controlled experiment. J Pain 2012, 13, 1206-1214.

7. Shefner, J. M., Berman, S.A., Young, R. R. The effect of nicotine on recurrent inhibition in the spinal cord. Neurology 1993, $43,2647-2651$.

8. Cordero-Erausquin, M., Pons, S., Faure, P., Changeux, J. P. Nicotine differentially activates inhibitory and excitatory neurons in the dorsal spinal cord. Pain 2004, 109, 308-318.

9. Matsumoto, M., Xie, W., Inoue, M., Ueda, H. Evidence for the tonic inhibition of spinal pain by nicotinic cholinergic transmission through primary afferents. Mol Pain 2007, 3, 41.

10. Preedy, V. R. Neuroscience of Nicotine. Academic Press, London 2019, 1-544. https://doi.org/10.1016/C2016-0-03977-3.

11. Jobson, C. L. M., Renard, J., Szkudlarek, H., Rosen, L. G., Pereira, B., Wright, D. J., Rushlow, W., Laviolette, S. R. Adolescent Nicotine Exposure Induces Dysregulation of Mesocorticolimbic Activity States and Depressive and Anxiety-like Prefrontal Cortical Molecular Phenotypes Persisting into Adulthood. Cereb Cortex 2019, 29, 3140-3153.

12. Damaj, M. I., Glassco, W., Dukat, M., Martin, B.R. Pharmacological characterization of nicotine-induced seizures in mice. J Pharmacol Exp Ther 1999, 291, 1284-1291.

13. Iha, H. A., Kunisawa, N., Shimizu, S., Tokudome, K., Mukai, T., Kinboshi, M., Ikeda, A., Ito, H., Serikawa, T., Ohno, Y. Nicotine Elicits Convulsive Seizures by Activating Amygdalar Neurons. Front. Pharmacol 2017, 8, 57. 
14. Inestrosa, N. C., Godoy, J. A., Vargas, J. Y., Arrazola, M. S., Rios, J. A., Carvajal, F. J., Serrano, F. G., Farias, G. G. Nicotine prevents synaptic impairment induced by amyloid-beta oligomers through alpha7-nicotinic acetylcholine receptor activation. Neuromolecular Med 2013, 15, 549-569.

15. Sakurai, R., Cerny, L. M., Torday, J. S., Rehan, V. K. Mechanism for nicotine-induced up-regulation of Wnt signaling in human alveolar interstitial fibroblasts. Exp Lung Res 2011 37, 144-1454.

16. Gordon, M. D., Nusse, R. Wnt signaling: multiple pathways, multiple receptors, and multiple transcription factors. J Biol Chem 2006 281, 22429-2233.

17. Shinozuka, T., Takada, R., Yoshida, S., Yonemura, S., Takada, S. Wnt produced by stretched roof-plate cells is required for the promotion of cell proliferation around the central canal of the spinal cord. Development 2019 146, dev159343.

18. Megason, S. G., McMahon, A. P. A mitogen gradient of dorsal midline Wnts organizes growth in the CNS. Dev. Camb. Engl. 2002, 129, 2087-2098.

19. Nusse, R., Clevers, H. Wnt/3-Catenin Signaling, Disease, and Emerging Therapeutic Modalities. Cell 2017, 169, 985-999.

20. Muroyama, Y., Fujihara, M., Ikeya, M., Kondoh, H., Takada, S. Wnt signaling plays an essential role in neuronal specification of the dorsal spinal cord. Genes Dev 2002 16, 548-553.

21. Liu, Y., Wang, X., Lu, C. C., Kerman, R., Steward, O., Xu, X. M., Zou, Y. Repulsive Wnt signaling inhibits axon regeneration after CNS injury. J. Neurosci 2008, 28, 8376-8382.

22. Yang, Q. O., Yang, W. J., Li, J., Liu, F. T., Yuan, H., Ou Yang, Y. P. Ryk receptors on unmyelinated nerve fibers mediate excitatory synaptic transmission and CCL2 release during neuropathic pain induced by peripheral nerve injury. Mol. Pain 2017, 13, 1744806917709372.

23. González, P., Fernández-Martos, C. M., Arenas, E., and Rodríguez, F. J. The Ryk receptor is expressed in glial and fibronectin-expressing cells after spinal cord injury. J. Neurotrauma 2013, 30, 806-817.

24. Tang, J., Ji, Q., Jin, L., Tian, M., Zhang, L. D., Liu, X. Y. Secreted frizzled-related protein 1 regulates the progression of neuropathic pain in mice following spinal nerve ligation. J. Cell. Physiol 2018, 233, 5815-5822.

25. Gonzalez, P., Rodríguez, F. J. Analysis of the expression of the Wnt family of proteins and its modulatory role on cytokine expression in non activated and activated astroglial cells. Neurosci. Res 2017, 114, 16-29.

26. Fernández-Martos, C. M., González-Fernández, C., González, P., Maqueda, A., Arenas, E., and Rodríguez, F. J. Differential expression of Wnts after spinal cord contusion injury in adult rats. PloS One 2011, 6, e27000.

27. Wei, L., Chen, C., Ding, L., Mo, M., Zou, J., Lu, Z., Li, H., Wu, H., Dai, Y., Xu, P., et al. Wnt1 Promotes EAAT2 Expression and Mediates the Protective Effects of Astrocytes on Dopaminergic Cells in Parkinson's Disease. Neural Plast 2019, 1247276. doi: 10.1155/2019/1247276.

28. Wang, X., Shi, S. H., Yao, H. J., Jing, Q. K., Mo, Y. P., Lv, W., Song, L. Y., Yuan, X. C., Li, Z. G., Qin, L. N. Electroacupuncture at Dazhui (GV14) and Mingmen (GV4) protects against spinal cord injury: the role of the Wnt/ $/$-catenin signaling pathway. Neural Regen Res 2016, 11, 2004-2011.

29. Lewis, A. E., Vasudevan, H. N., O'Neill, A. K., Soriano, P., Bush, J. O. The widely used Wnt1-Cre transgene causes developmental phenotypes by ectopic activation of Wnt signaling. Dev Biol 2013, 379, 229-234.

30. Wang, D., Wu, F., Yuan, H., Wang, A., Kang, G. J., Truong, T., Chen, L., McCallion, A. S., Gong, X., Li, S. Sox10+Cells Contribute to Vascular Development in Multiple Organs-Brief Report. Arterioscler Thromb Vasc Biol 2017, 37, $1727-1731$.

31. Dunn, K. W., Kamocka, M. M., McDonald, J H. A practical guide to evaluating colocalization in biological microscopy. Am J Physiol Cell Physiol 2011, 300, C723-742.

32. Costes, S. V., Daelemans, D., Cho, E. H., Dobbin, Z., Pavlakis, G., Lockett, S. Automatic and quantitative measurement of protein-protein colocalization in live cells. Biophys J 2004, 86, 3993-4003.

33. Chikazawa, N., Tanaka, H., Tasaka, T., Nakamura, M., Tanaka, M., Onishi, H., Katano, M. Inhibition of Wnt Signaling Pathway Decreases Chemotherapy-resistant Side-population Colon Cancer Cells. Anticancer Res 2010, 30, $2041-2048$.

34. Ki, D. H., Oppel, F., Durbin, A. D., and Look, A. T. Mechanisms underlying synergy between DNA topoisomerase I-targeted drugs and mTOR kinase inhibitors in NF1-associated malignant peripheral nerve sheath tumors. Oncogene 2019, 38, 65856598.

35. Grillner, S. Biological pattern generation: the cellular and computational logic of networks in motion. Neuron 2006, 52, 751766.

36. Kiehn, O. Locomotor circuits in the mammalian spinal cord. Annu Rev Neurosci 2006, 29, 279-306.

37. Blutstein, T., Castello, M. A., Viechweg, S. S., Hadjimarkou, M. M., McQuail, J. A., Holder, M., Thompson, L. P., Mong, J. A. Differential Responses of Hippocampal Neurons and Astrocytes to Nicotine and Hypoxia in the Fetal Guinea Pig. Neurotox Res 2013, 24, 80-93.

38. Slotkin, T. A. Cholinergic systems in brain development and disruption by neurotoxicants: nicotine, environmental tobacco smoke, organophosphates. Toxicology and applied pharmacology 2004, 198, 132-151.

39. Marchetti, C., Beato, M., Nistri, A. Alternating rhythmic activity induced by dorsal root stimulation in the neonatal rat spinal cord in vitro. Journal of Physiology 2001, 530, 105-112. 
40. Cazalets, J. R., Sqalli-Houssaini, Y., Clarac, F. Activation of the central pattern generators for locomotion by serotonin and excitatory amino acids in neonatal rat. Journal of Physiology 1992, 455, 187-204.

41. Gillies, J. D., Lance, J. W., Neilson, P. D., \& Tassinari, C. A. Presynaptic inhibition of the monosynaptic reflex by vibration. Journal of physiology 1969, 205, 329-339.

42. Kiehn, O. Decoding the organization of spinal circuits that control locomotion. Nature Reviews Neuroscience 2016, 17, 224238.

43. Wollman, L. B., Levine, R. B., Fregosi, R. F. Developmental plasticity of GABAergic neurotransmission to brainstem motoneurons. J Physiol 2018a, 596, 5993-6008.

44. Wollman, L. B., Levine, R. B., Fregosi, R. F. Developmental nicotine exposure alters glycinergic neurotransmission to hypoglossal motoneurons in neonatal rats. J Neurophysiol 2018b, 120, 1135-1142.

45. Wollman, L. B., Clarke, J., DeLucia, C. M., Levine, R. B., Fregosi, R.F. Developmental Nicotine Exposure Alters Synaptic Input to Hypoglossal Motoneurons and Is Associated with Altered Function of Upper Airway Muscles. eNeuro 2019, 6, ENEURO.0299-19.2019.

46. Ai, F., Zhang, Y., Peng, B. Restoration of miR-98 relieves the inhibitory effect of nicotine on the differentiation of P19 cells into cardiomyocytes. Biotechnol. Lett 2016, 38, 579-587.

47. Zou, W., Zou, Y., Zhao, Z., Li, B., Ran, P. Nicotine-induced epithelial-mesenchymal transition via Wnt/b-catenin signaling in human airway epithelial cells. Am J Physiol Lung Cell Mol Physiol 2013, 304, L199-L209.

48. Lemjabbar-Alaoui, H., Dasari, V., Sidhu, S. S., Mengistab, A., Finkbeiner, W., Gallup, M., Basbaum, C. Wnt and Hedgehog are critical mediators of cigarette smoke-induced lung cancer. PLoS One 2006, 1, e93.

49. Wang, R., Ahmed, J., Wang, G., Hassan, I., Strulovici-Barel, Y., Hackett, N. R., Crystal, R. G. Down-Regulation of the Canonical Wnt b-Catenin Pathway in the Airway Epithelium of Healthy Smokers and Smokers with COPD. PLoS One 2011, 6, e14793.

50. Mazzone, G. L., Nistri, A. S100 $\beta$ as an early biomarker of excitotoxic damage in spinal cord organotypic cultures. Journal of Neurochemistry 2014, 130, 598-604.

51. Zhao, Y., Zhang, Q., Xi, J., Xiao, B., Li, Y., Ma, C. Neuroprotective effect of fasudil on inflammation through PI3K/Akt and Wnt/B-catenin dependent pathways in a mice model of Parkinson's disease. Int J Clin Exp Pathol 2015, 8, $2354-2364$.

52. L'Episcopo, F., Tirolo, C., Testa, N., Caniglia, S., Morale, M. C., Cossetti, C., D'Adamo, P., Zardini, E., Andreoni, L., Ihekwaba, A. E., Serra, P. A., Franciotta, D., Martino, G., Pluchino, S., Marchetti, B. Reactive astrocytes and Wnt $/ \beta$-catenin signaling link nigrostriatal injury to repair in 1-methyl-4-phenyl-1,2,3,6-tetrahydropyridine model of Parkinson's disease. Neurobiol Dis 2011, 41, 508-527.

53. Simonetti, M., Kuner, R. Spinal Wnt5a Plays a Key Role in Spinal Dendritic Spine Remodeling in Neuropathic and Inflammatory Pain Models and in the Proalgesic Effects of Peripheral Wnt3a. J Neurosci 2020, 40, 6664-6677.

54. Alrefaei, A. F., Münsterberg, A. E., Wheeler, G. N. FZD10 regulates cell proliferation and mediates Wnt1 induced neurogenesis in the developing spinal cord. PLoS One 2020, 15, e0219721.

55. Cifra, A., Mazzone, G. L., Nani, F., Nistri, A., Mladinic, M. Postnatal developmental profile of neurons and glia in motor nuclei of the brainstem and spinal cord, and its comparison with organotypic slice cultures. Dev. Neurobiol 2012, 72, 11401160.

56. Berg, D. K., Conroy, W. G. Nicotinic alpha 7 receptors: synaptic options and downstream signaling in neurons. J Neurobiol 2002, 53, 512-523.

57. Hsu, Y. N., Edwards, S. C., Wecker, L. Nicotine enhances the cyclic AMP-dependent protein kinase-mediated phosphorylation of alpha4 subunits of neuronal nicotinic receptors. J Neurochem 1997, 69, 2427-2431.

58. Takeda, D., Nakatsuka, T., Gu, J. G., Yoshida, M. The activation of nicotinic acetylcholine receptors enhances the inhibitory synaptic transmission in the deep dorsal horn neurons of the adult rat spinal cord. Mol. Pain 2007, 3, 26.

59. Mazzone, G. L., Margaryan, G., Kuzhandaivel, A., Nasrabady, S. E., Mladinic, M., Nistri, A. Kainate-induced delayed onset of excitotoxicity with functional loss unrelated to the extent of neuronal damage in the in vitro spinal cord. Neuroscience 2010, 168, 451-462.

60. Mazzone, G. L., Veeraraghavan, P., Gonzalez-Inchauspe, C., Nistri, A., and Uchitel, O. D. ASIC channel inhibition enhances excitotoxic neuronal death in an in vitro model of spinal cord injury. Neuroscience 2017, 343, 398-410.

61. Kuzhandaivel, A., Nistri, A., Mazzone, G. L., Mladinic, M. Molecular Mechanisms Underlying Cell Death in Spinal Networks in Relation to Locomotor Activity After Acute Injury in vitro. Front Cell Neurosci 2011, 5, 9.

62. Margaryan, G., Mladinic, M., Mattioli, C., \& Nistri, A. Extracellular magnesium enhances the damage to locomotor networks produced by metabolic perturbation mimicking spinal injury in the neonatal rat spinal cord in vitro. Neuroscience 2009, 163, 669-682.

63. Petrović, A., Kaur, J., Tomljanović, I., Nistri, A., Mladinic, M. Pharmacological induction of Heat Shock Protein 70 by celastrol protects motoneurons from excitotoxicity in rat spinal cord in vitro. Eur J Neurosci 2019, 49, 215-231. 
64. Sierra, R., Bustillo, S. G., Kameneva, P., Fiore, E. J., Mazzone, G. L., Borda, M., Blanco, M. V., Usuardi, C., Furlan, A., Ernfors, P., et al. Contribution of neural crest and GLAST+ Wnt1+ bone marrow pericytes with liver fibrogenesis and/or regeneration. Liver Int 2020, 40, 977-987.

65. Baranauskas, G., Nistri A. Effects of RP 67580 on substance P-elicited responses and postsynaptic potentials of motoneurones of the rat isolated spinal cord. Peptides 1995, 16, 357-359.

66. Ostroumov, K., Grandolfo, M., Nistri, A. The effects induced by the sulphonylurea glibenclamide on the neonatal rat spinal cord indicate a novel mechanism to control neuronal excitability and inhibitory neurotransmission. Br J Pharmacol 2007, 150, 47-57.

67. Kaur, J., Flores, G. J., Nistri, A. Neuroprotective effect of propofol against excitotoxic injury to locomotor networks of the rat spinal cord in vitro. Eur J Neurosci 2016, 44, 2418-2430.

68. Sámano, C., Kaur, J., Nistri, A. A study of methylprednisolone neuroprotection against acute injury to the rat spinal cord in vitro. Neuroscience 2016, 315, 136-149.

69. El Waly, B., Escarrat, V., Perez-Sanchez, J., Kaur, J., Pelletier, F., Collazos-Castro, J. E., Debarbieux, F. Intravital Assessment of Cells Responses to Conducting Polymer-Coated Carbon Microfibres for Bridging Spinal Cord Injury. Cells 2021, $10,73$.

70. Kaur, J., Conti, E. Dataset on inflammation induced after lumbar puncture. Data in Brief 2021,34, 106729.

71. Mazzone, G. L., Mladinic, M., Nistri, A. Excitotoxic cell death induces delayed proliferation of endogenous neuroprogenitor cells in organotypic slice cultures of the rat spinal cord._Cell Death Dis 2013, 4, e902.

72. Nasrabady, S. E., Kuzhandaivel, A., \& Nistri, A. Studies of lo- comotor network neuroprotection by the selective poly (ADPribose) polymerase-1 inhibitor PJ-34 against excitotoxic injury to the rat spi- nal cord in vitro. European Journal of Neuroscience 2011, 33, 2216-2227.

73. Shabbir, A., Bianchetti, E., \& Nistri, A. The volatile anesthetic methoxyflurane protects motoneurons against excitotoxicity in an in vitro model of rat spinal cord injury. Neuroscience 2015, 285, 269-280.

74. Kaur, J., Mojumdar, A. A Mechanistic Overview of Spinal Cord Injury, Oxidative DNA Damage Repair and Neuroprotective Therapies. Int J Neurosci 2021, 1-25. doi: 10.1080/00207454.2021.1912040. 